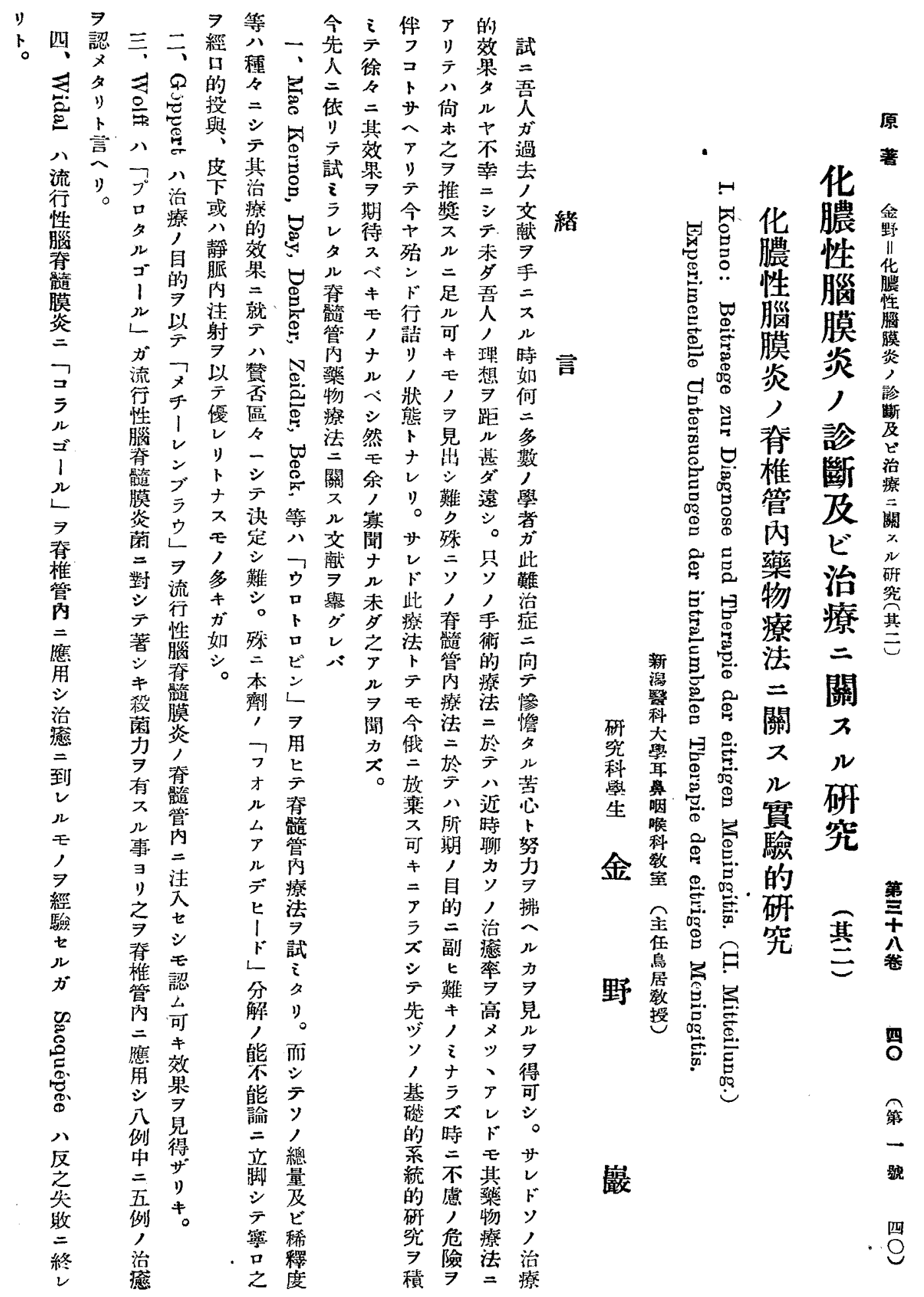




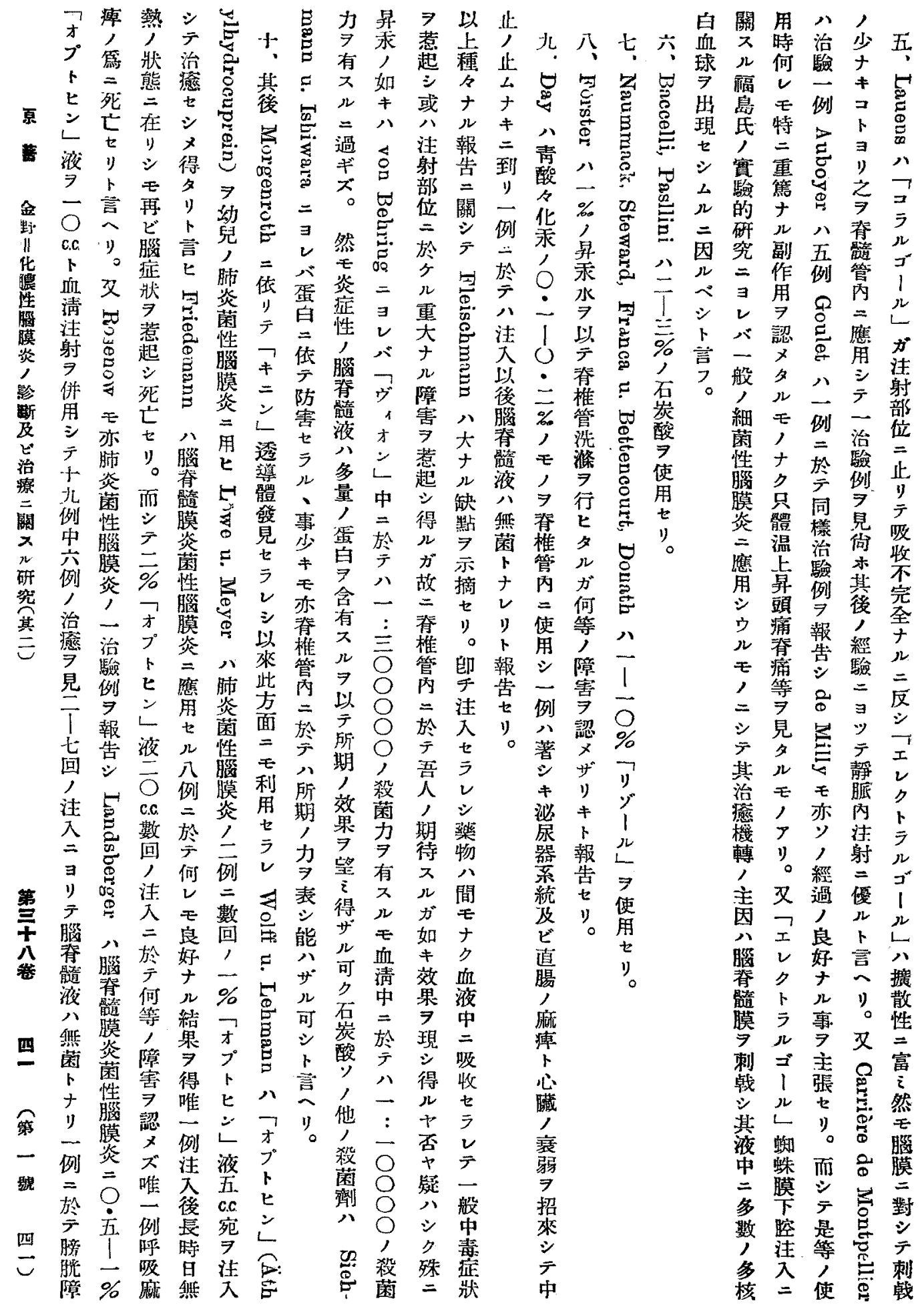




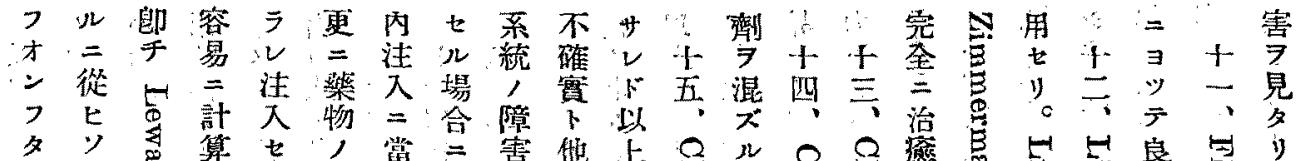

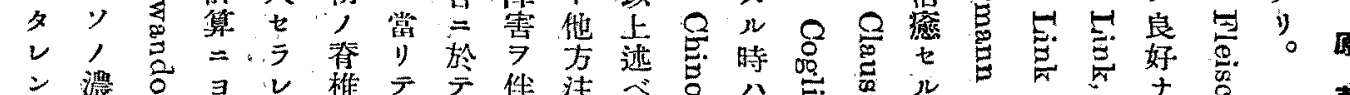

L蔗 妾

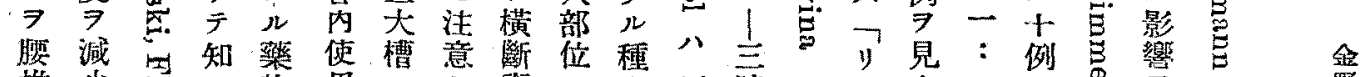

椎少兽出物用

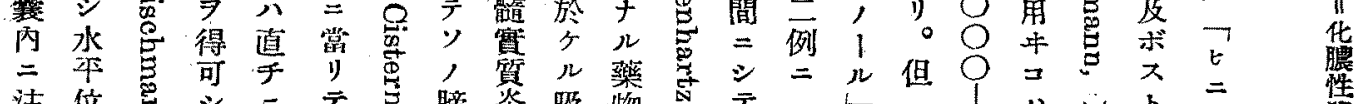

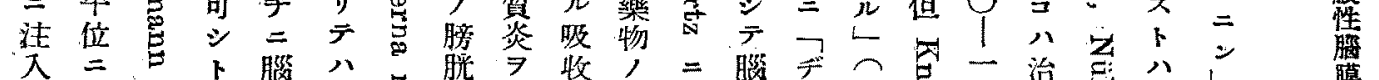

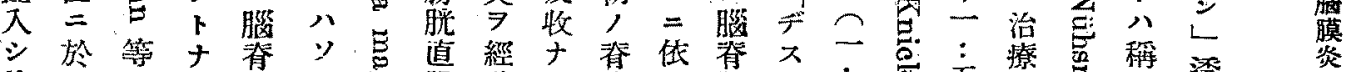

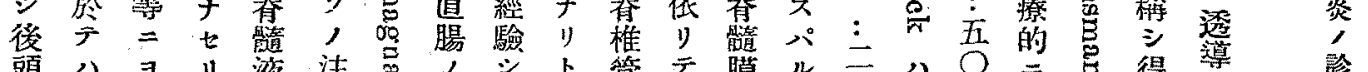

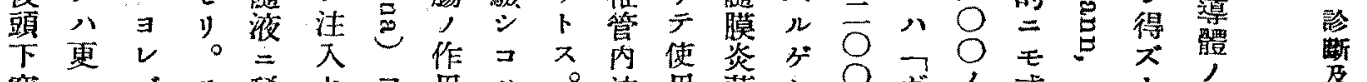

簌

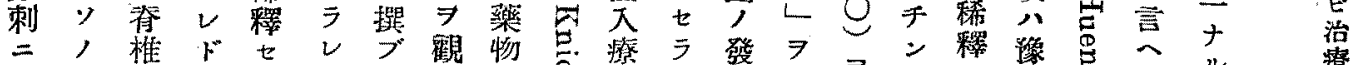

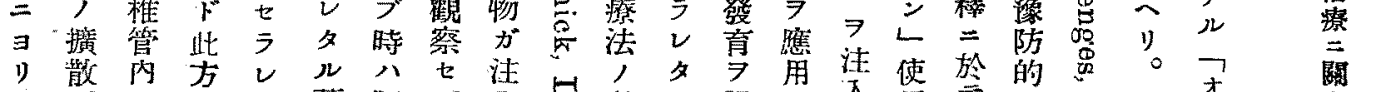

光馓内方

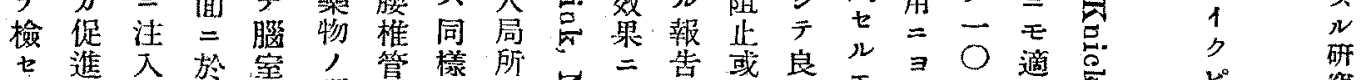

七進 入

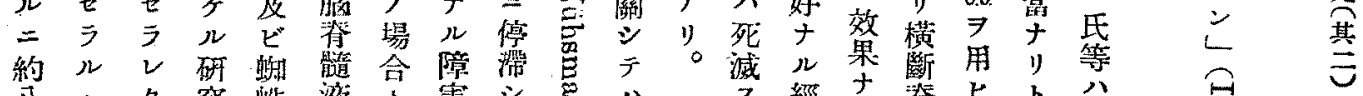

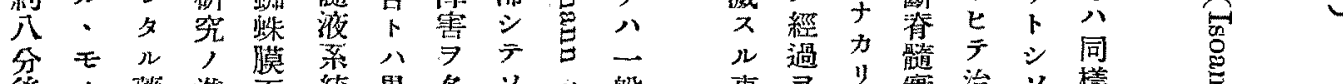

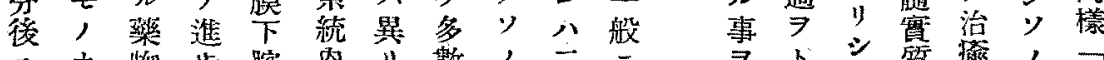

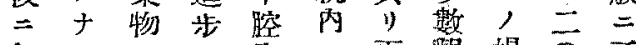

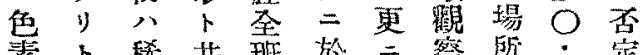

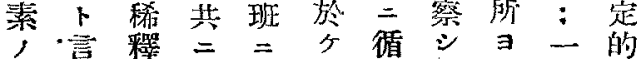

出

現 $\exists$, 等 態出可吸 $\bigcirc 7$

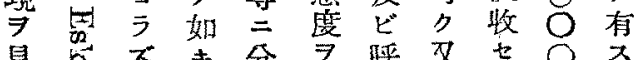

見点不分

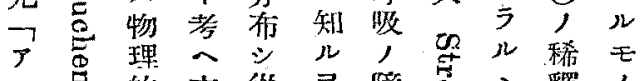

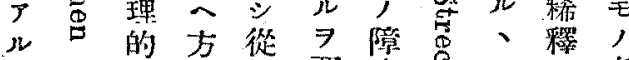

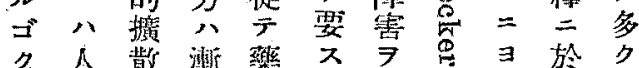

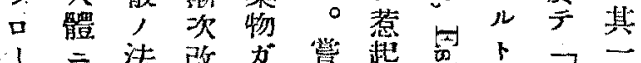

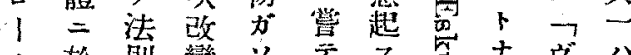

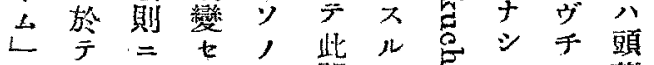

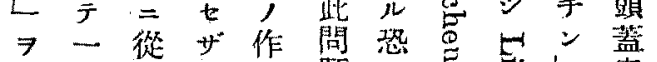

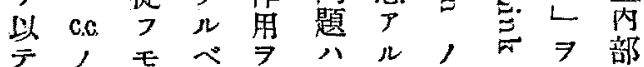

七刀, 力發極可言八使三

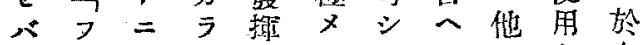

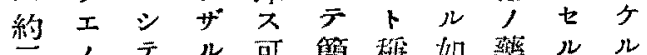

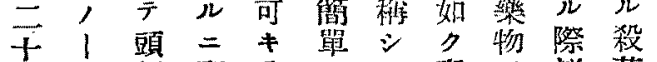

三部到分三夕春 7 沙菌

蚠

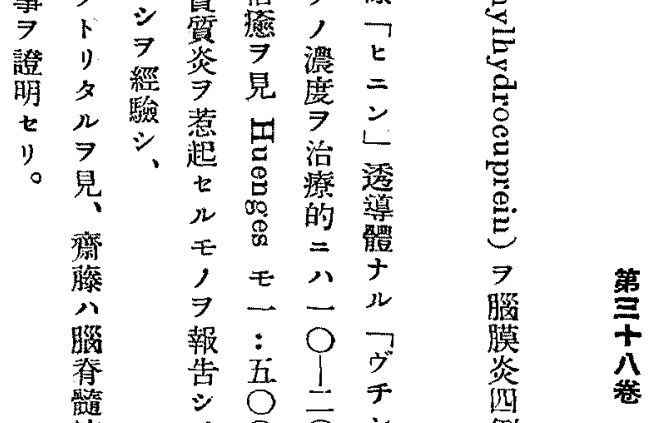

筜
公
聕
回

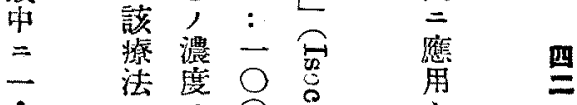

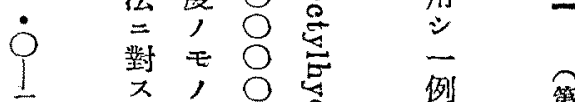

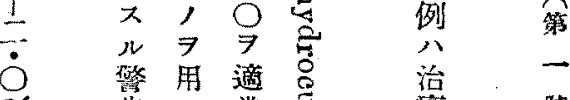

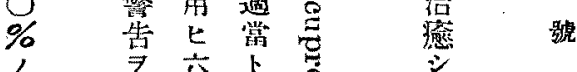

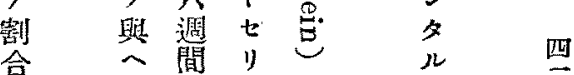

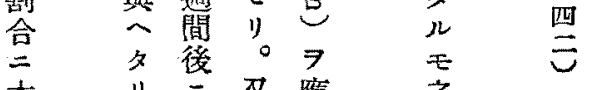


シ 最腦部二消十血物几平儿質二三八多腷還要

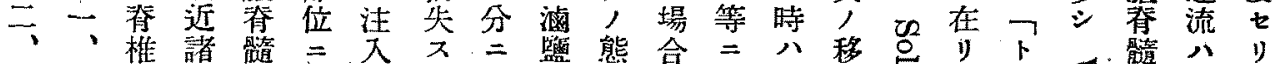
白注管標液此 原球七湶つ吸

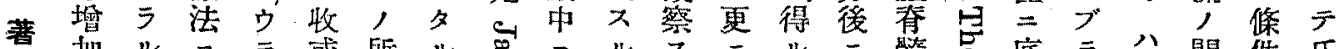
加 $=$ 或所

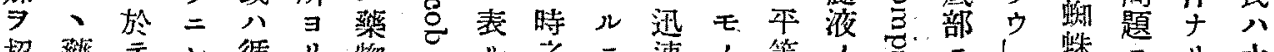

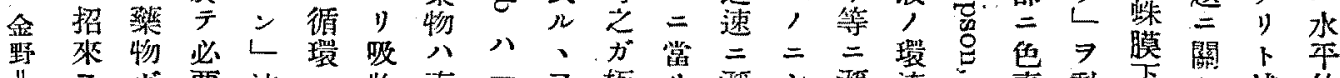

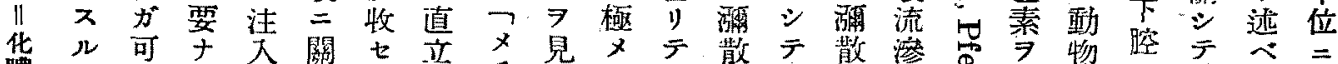

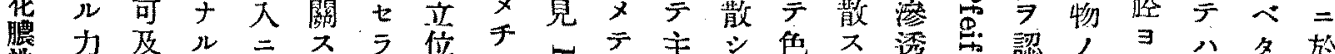

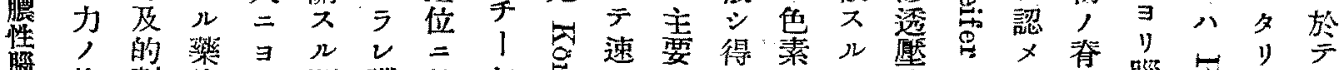

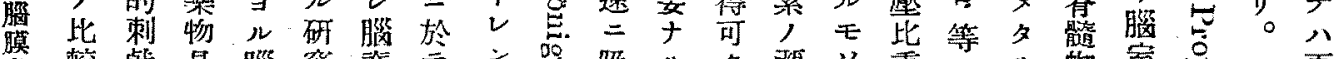

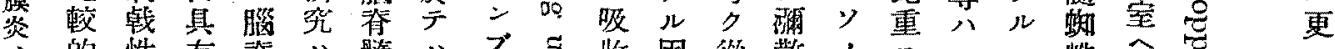

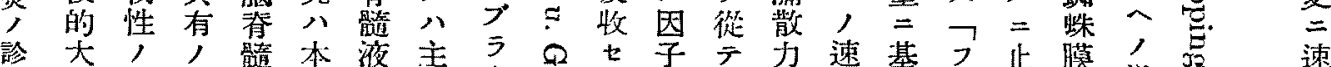

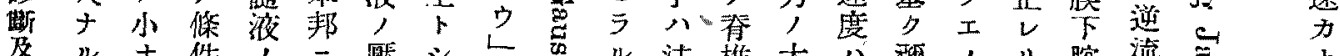

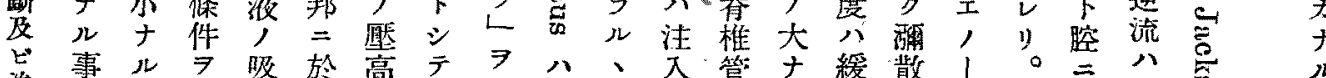
治事ル 7 吸 於高 潦 關
元
研
究
基
三

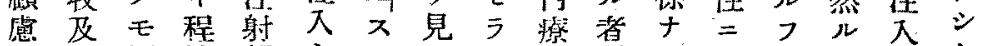
ス $ヒ$ 極速部 シ $゙$ N

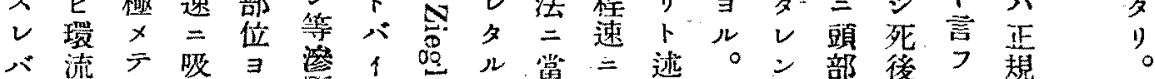

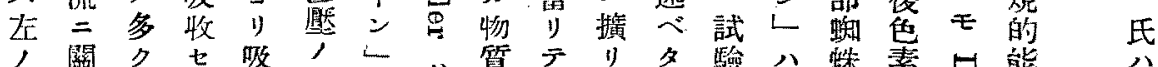
五 シ 小

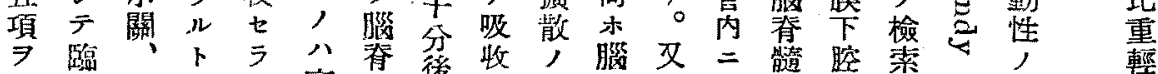

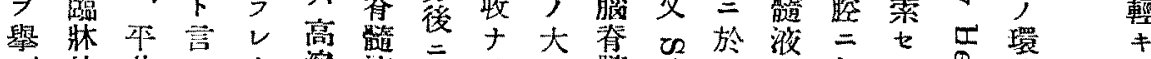

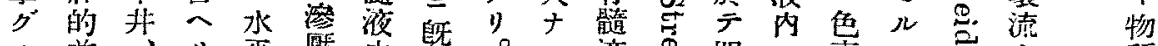

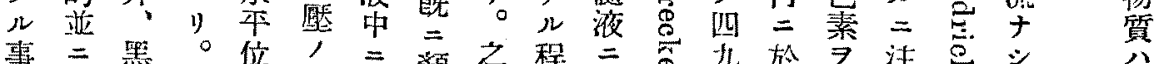

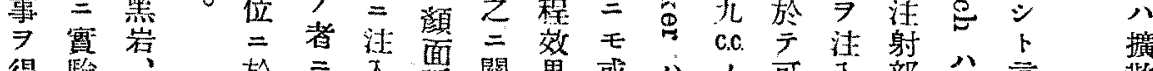

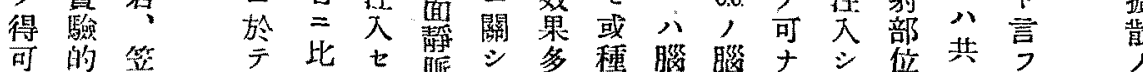

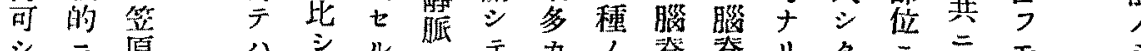

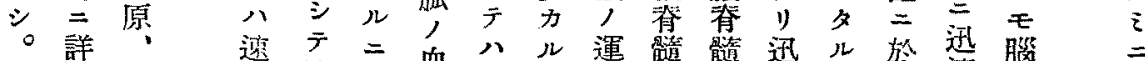

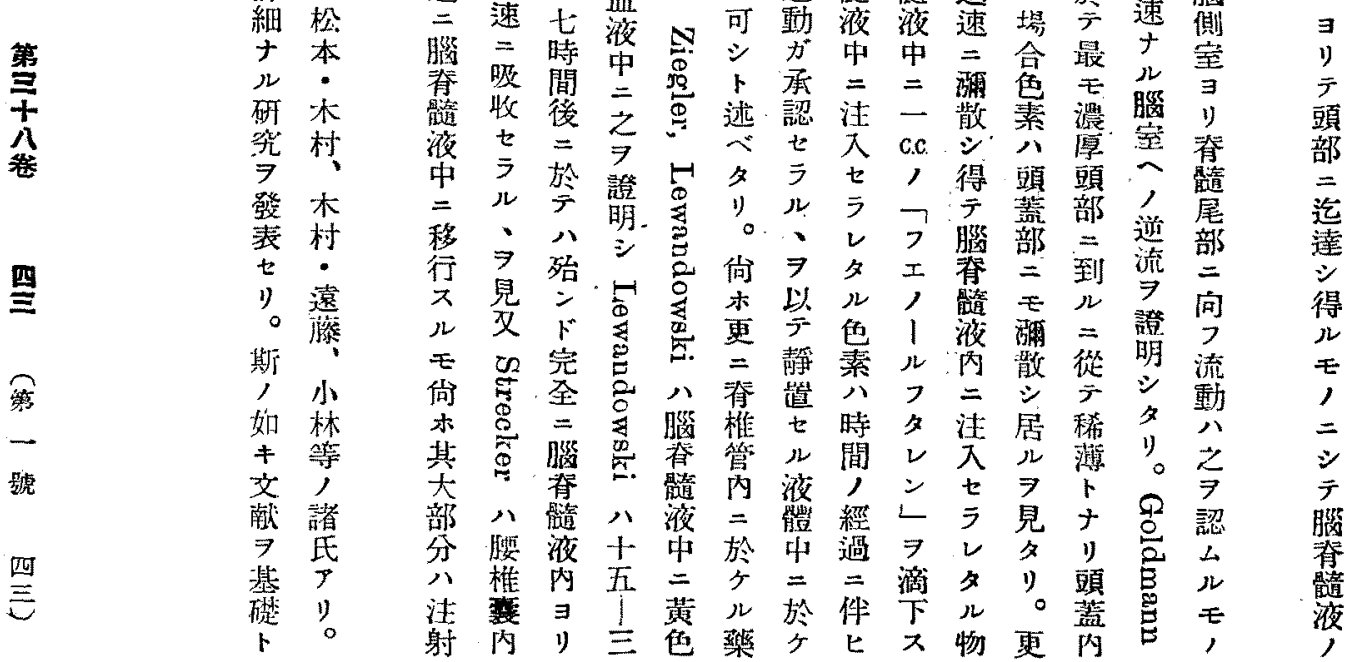




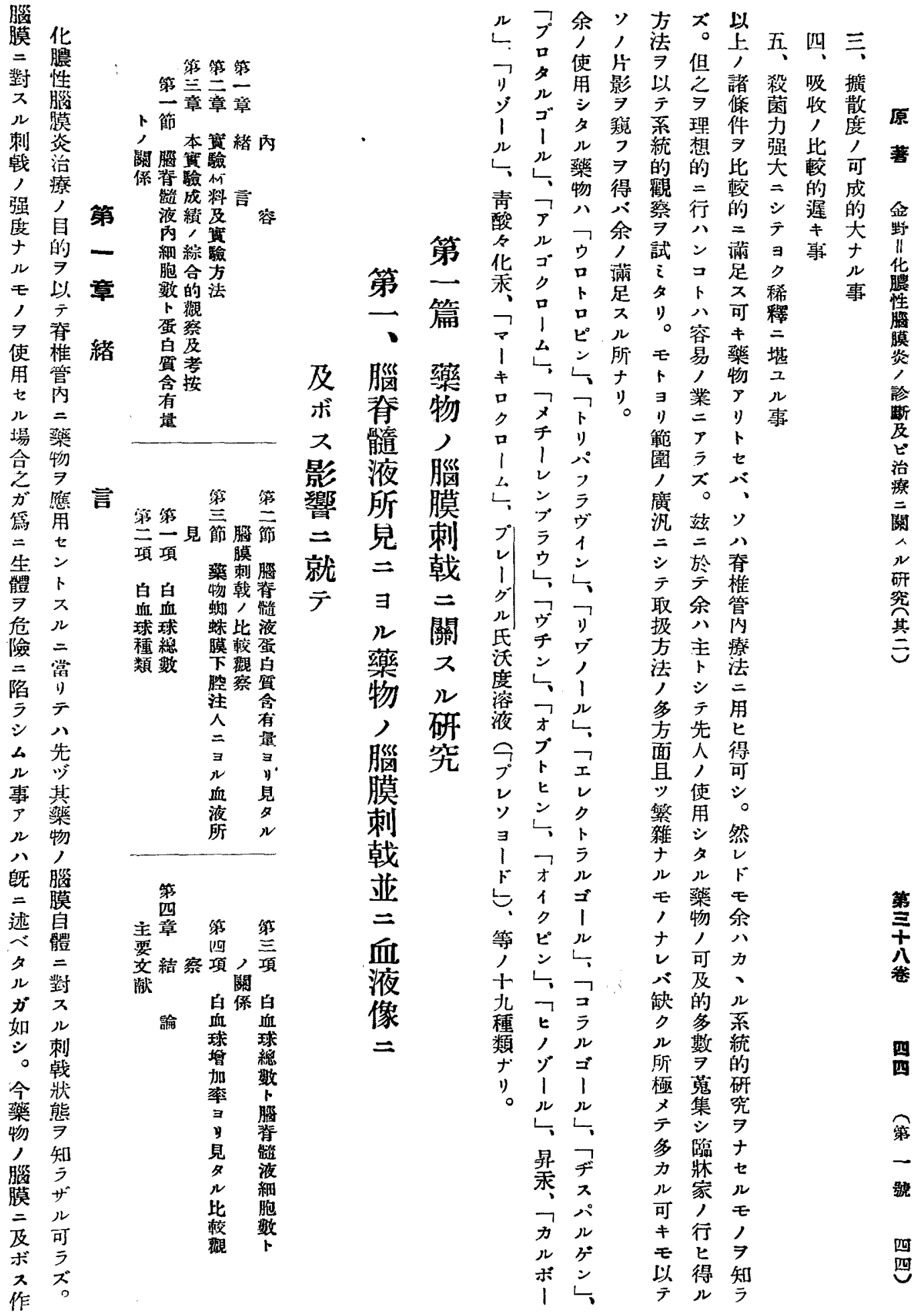




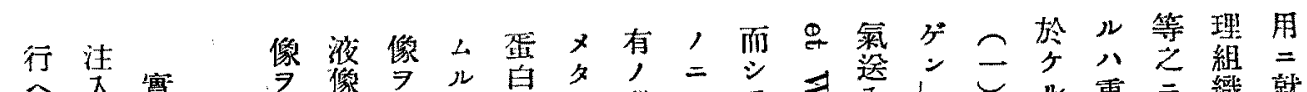

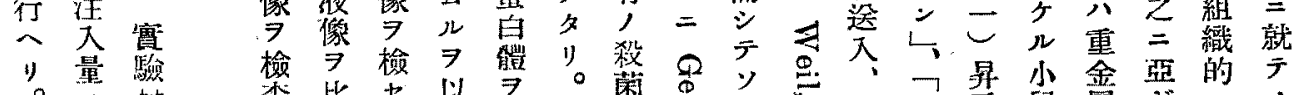

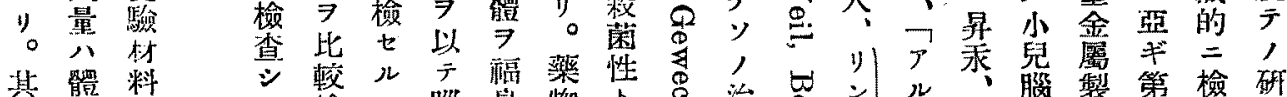
原甚重

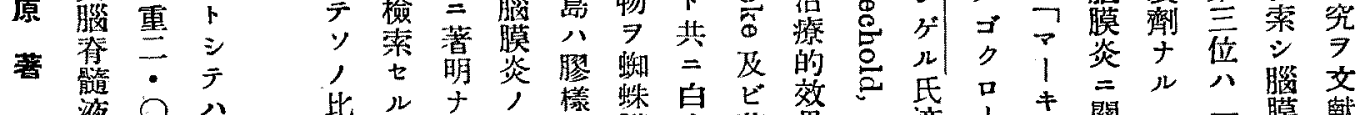

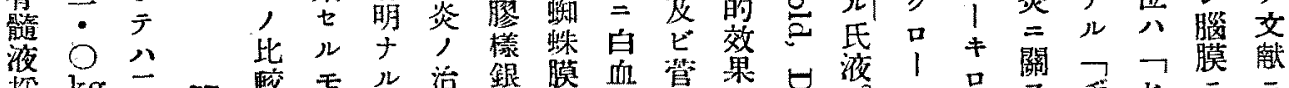

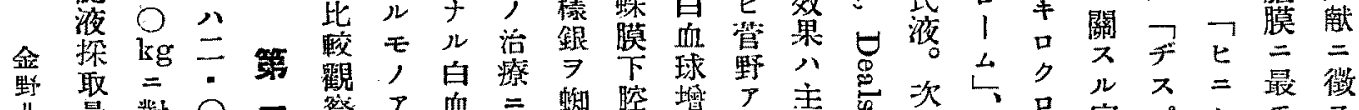

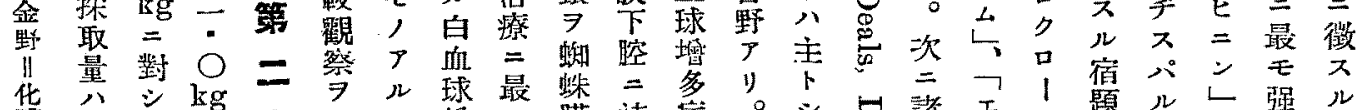

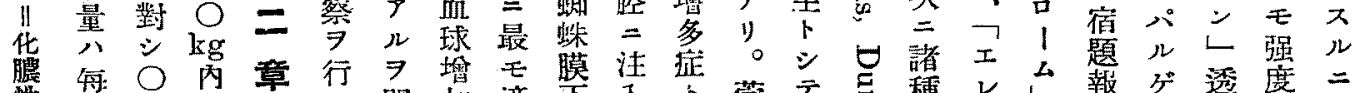
胜 每 9 常

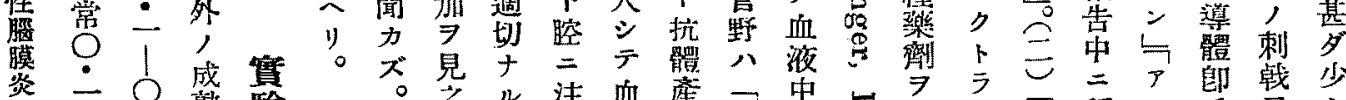

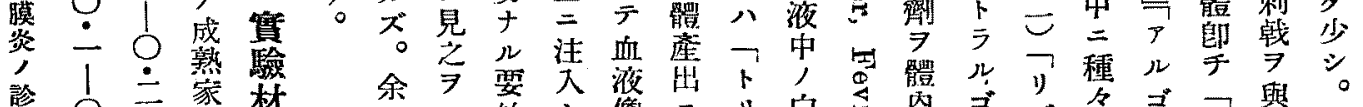

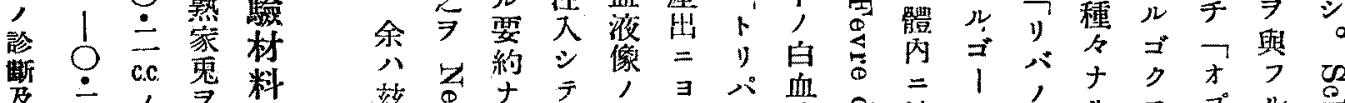

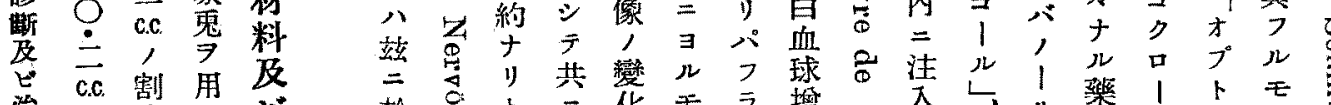

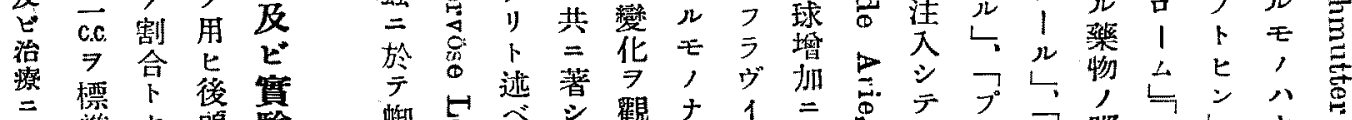

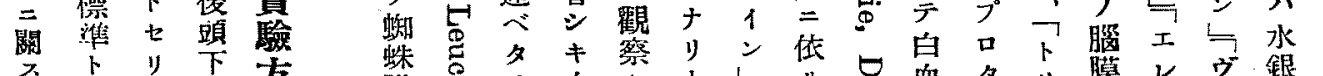

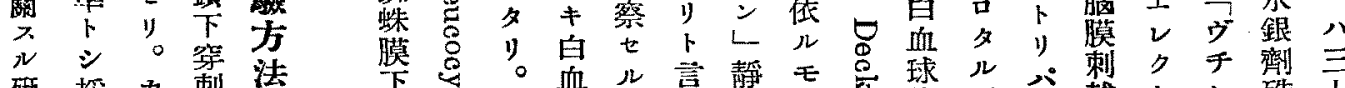

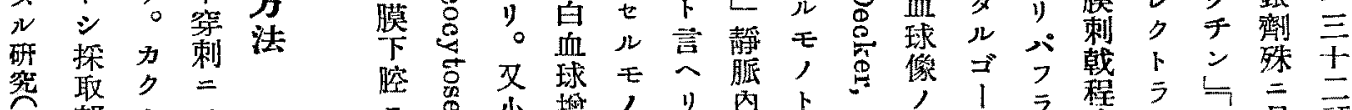
其 部 $シ \exists$ 㤩售後 可後 洼 及時 入 的間七 同三

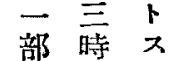
$\exists$ 間

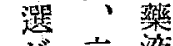

洼六時量

第射間

第㗊及同

公巷

$\mathrm{O}$ 四答

c. 時 䯕

四, 間潈

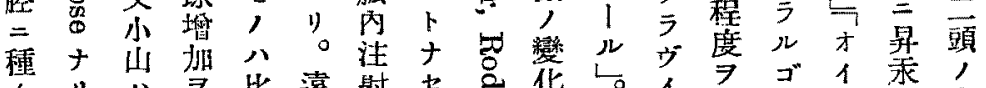

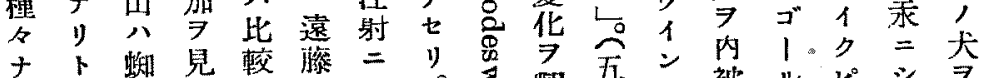

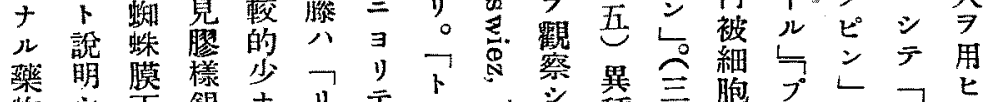

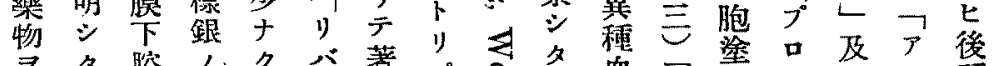

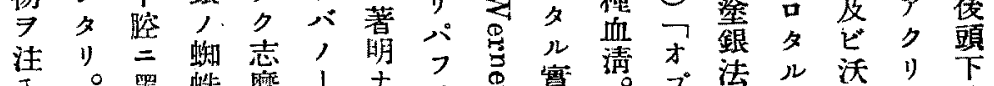

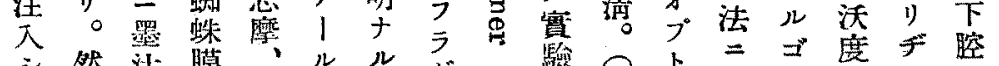

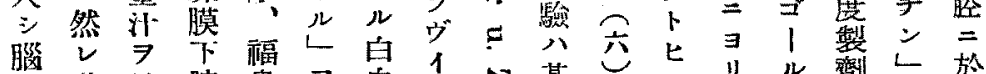

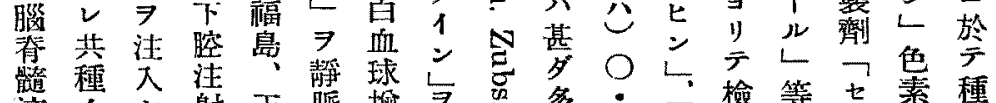

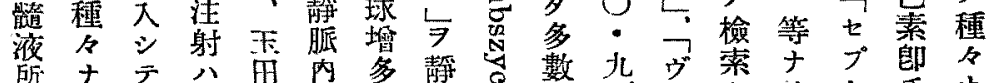

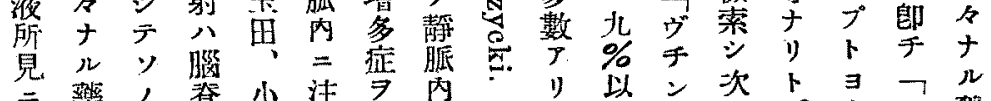

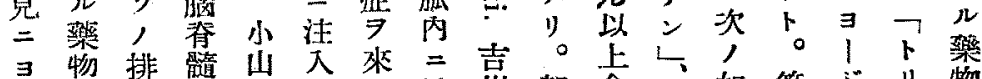
》 $\Rightarrow$ 蓝液 等

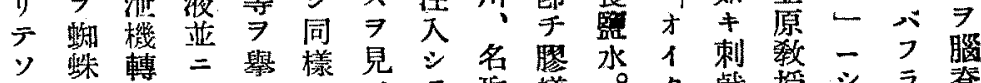

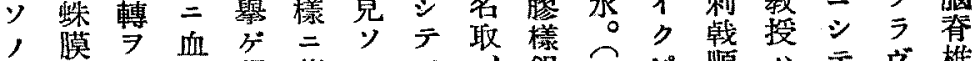
刺下檢液得著, y跟已ビ順分テヴ椎

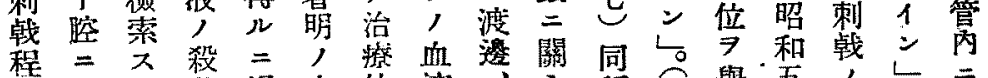

一分

躆至注 ᄂ 記 入

四射菑行

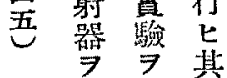

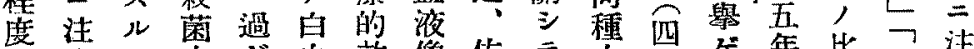
范

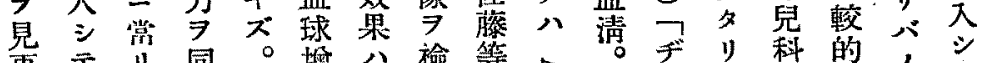

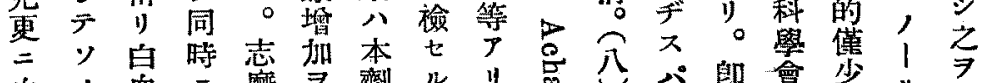

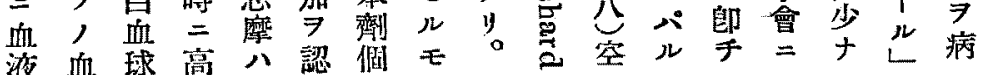




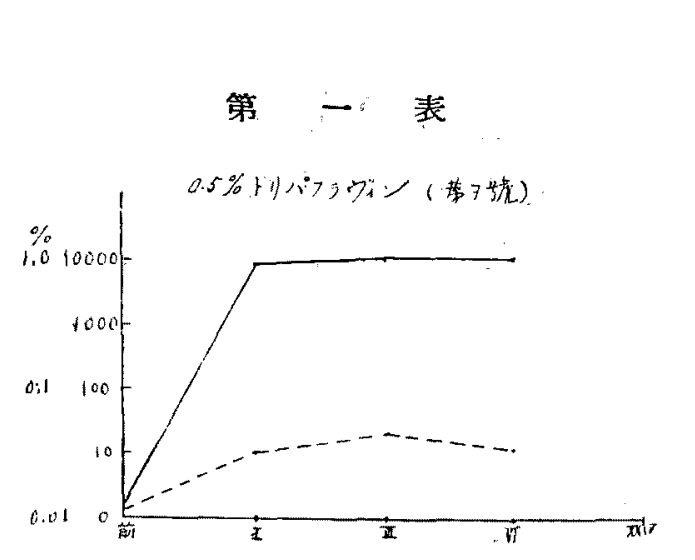

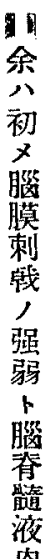

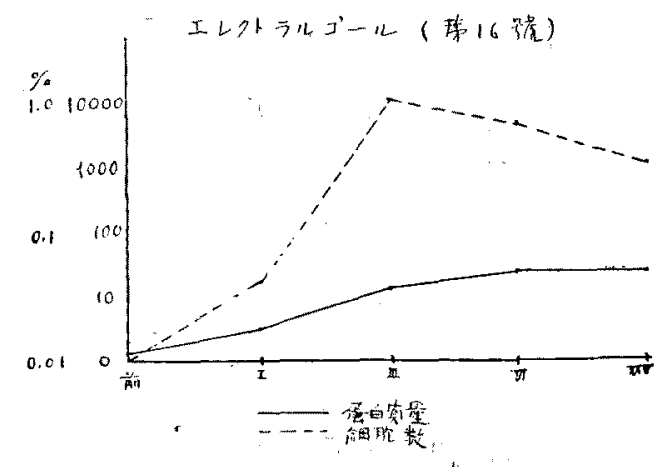

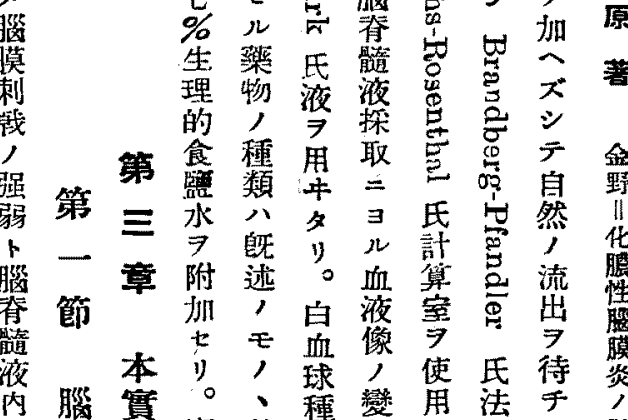

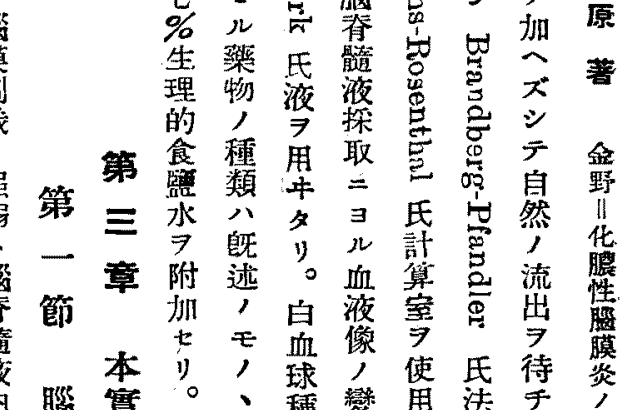

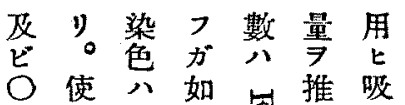

用与名定引

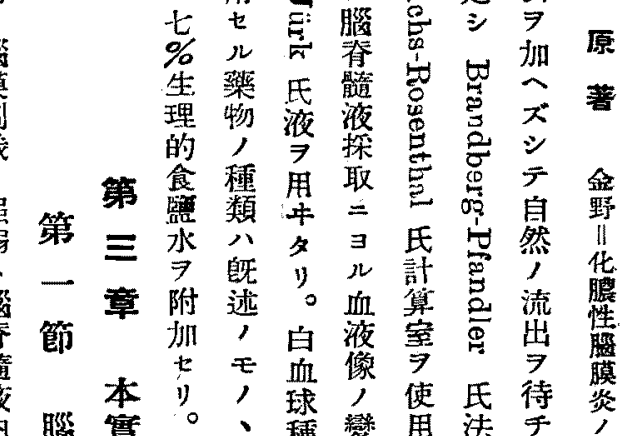

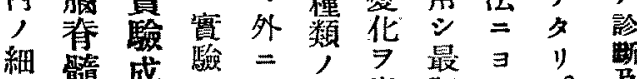

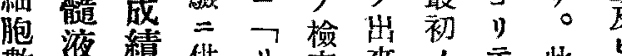

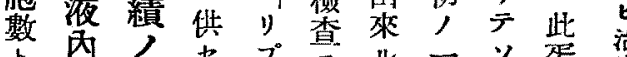

卜內ノ七プ旦少

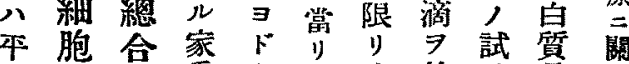

行數的鬼 | 劣捈驗量

シ

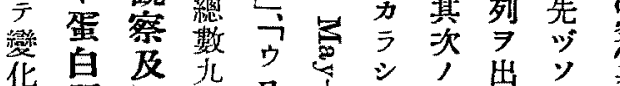

n

七 有

二進胞の著ズ合白ル質細モ事䦥

留

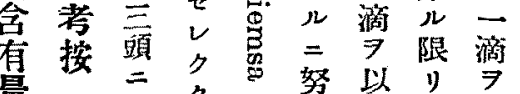

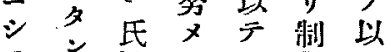

テ ᄂ 法夕七隄 テ

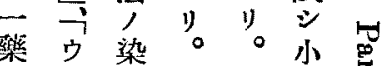

物三色自血量严

就 ン抹球像 淮 氏

キ L. 標總 檢 9 反

$\bar{\nabla} 7$ 本数查以雇

三加三人检每不检

考就檢常足检

頭, 每是腦

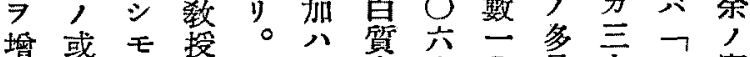

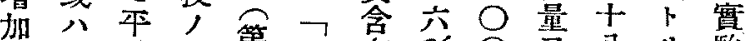

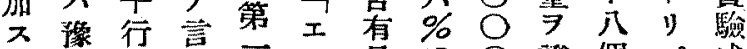

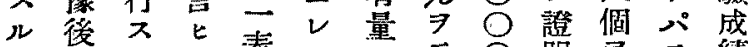

事条爪シ表々公示

實良モ。如藷

卜ナ, 此ラシ二越ルスヴリ

髺ル二遗關ルキ過ス=ル1見

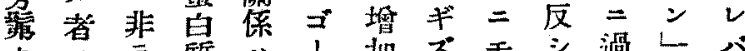

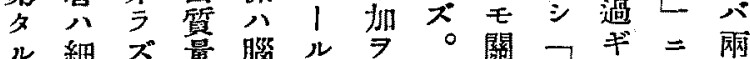

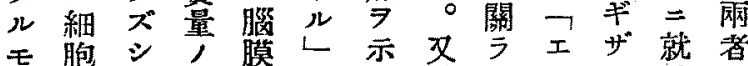

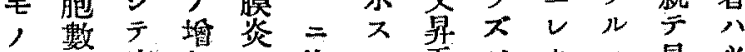

了, 病加 $=$ 比 $=$ 永

り。如稑占就 シ 關方

，他常八春ザ，

使對三曰崤ル反

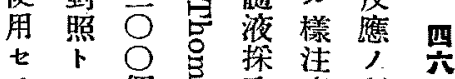

》三個嘉取意程

テ $\Rightarrow N$ 以

反 算 量前前。第

琵

艮平計

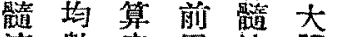

液 數空时㴕體

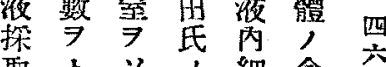

取卜”訔細含

西 

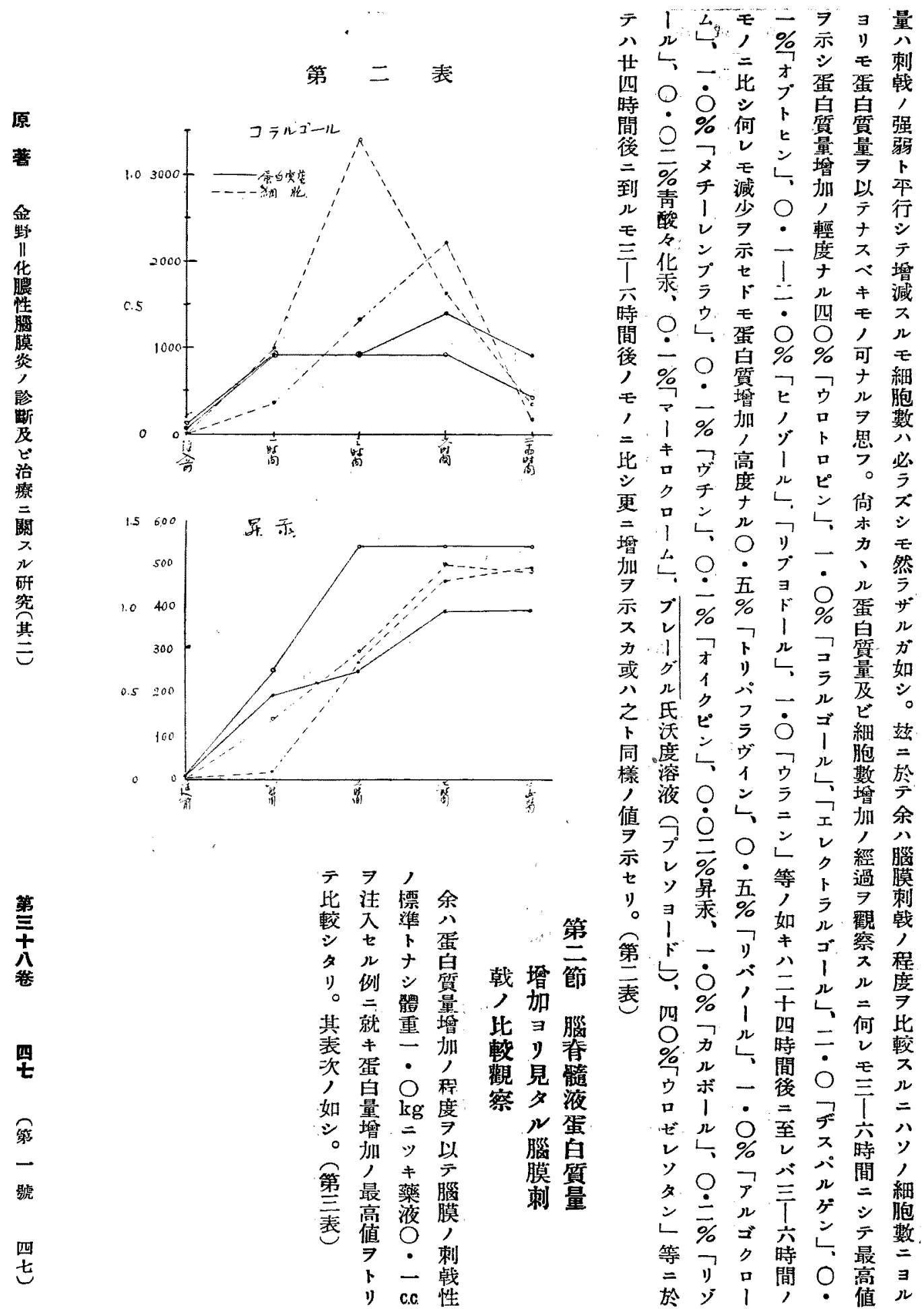


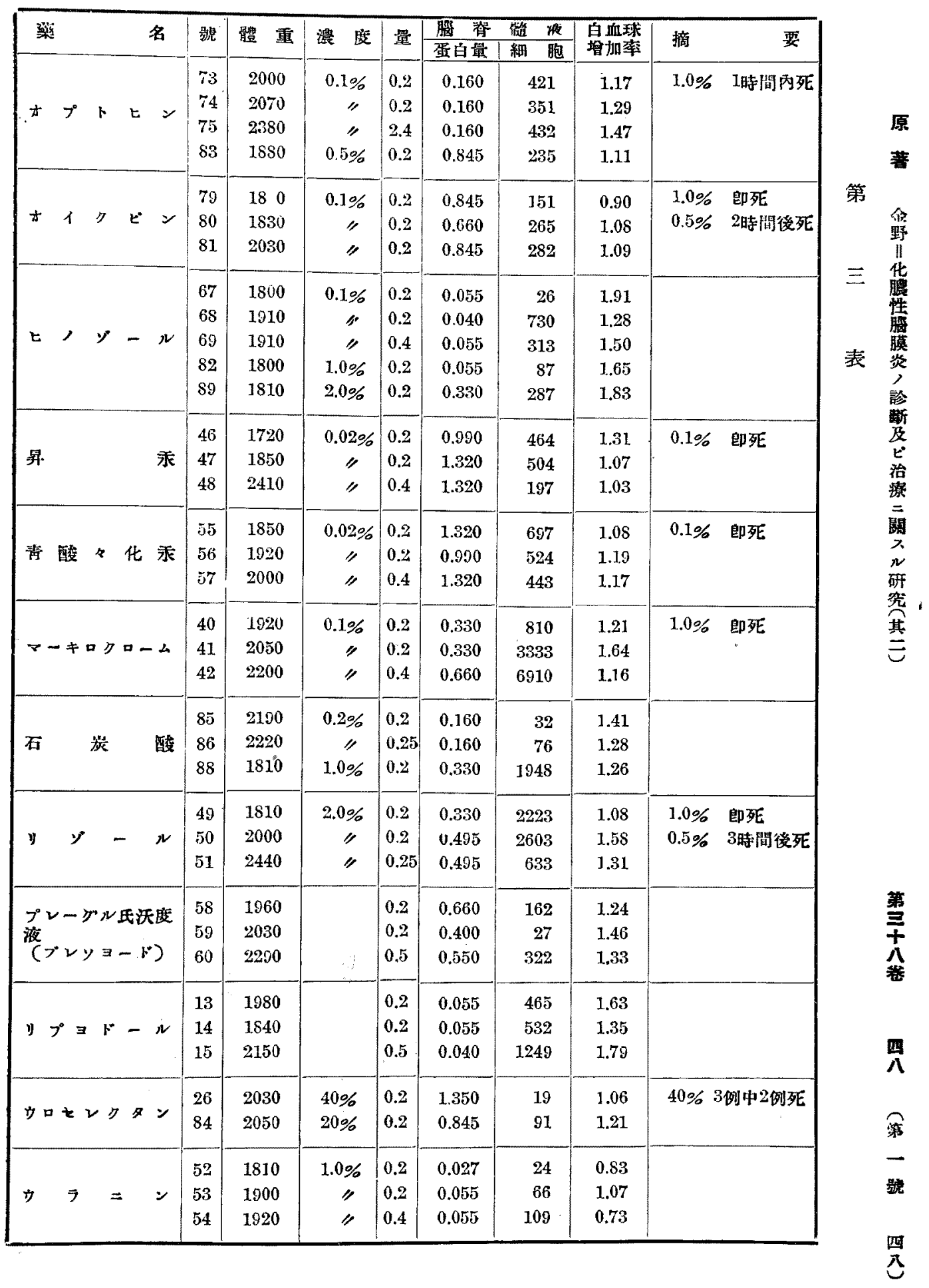




\begin{tabular}{|c|c|c|c|c|c|c|c|c|}
\hline 寀; ; 名： & 躆 & 䜺 重 & 波 洼 & 量 & 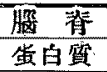 & $\begin{array}{ll}\text { 蹥 } & \text { 液 } \\
\text { 紐 } & \text { 胞 } \\
\end{array}$ & $\begin{array}{l}\text { 皇血球 } \\
\text { 管加率 }\end{array}$ & 摘 \\
\hline 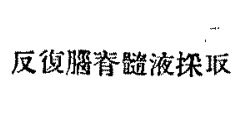 & $\begin{array}{l}91 \\
92 \\
93\end{array}$ & $\begin{array}{l}1800 \\
1870 \\
1920\end{array}$ & & & $\begin{array}{l}0.020 \\
0.0147 \\
0.0165\end{array}$ & $\begin{array}{l}7 \\
7 \\
2\end{array}$ & $\begin{array}{l}1.25 \\
0.97 \\
1.14\end{array}$ & \\
\hline 食醞水 & $\begin{array}{l}1 \\
2 \\
3\end{array}$ & $\begin{array}{l}1900 \\
1910 \\
1850\end{array}$ & $\begin{array}{c}0.7 \% \\
" \\
"\end{array}$ & $\begin{array}{l}0.2 \\
0.2 \\
0.5\end{array}$ & $\begin{array}{l}0.025 \\
0.020 \\
0.0165\end{array}$ & $\begin{array}{l}10 \\
23 \\
16\end{array}$ & $\begin{array}{l}1.18 \\
1.03 \\
1.29\end{array}$ & \\
\hline ウロトロビン & $\begin{array}{l}4 \\
5 \\
6\end{array}$ & $\begin{array}{l}2260 \\
2110 \\
2130\end{array}$ & $\begin{array}{r}40 \% \\
\geqslant\end{array}$ & $\begin{array}{l}2.25 \\
0.2 \\
2.5\end{array}$ & $\begin{array}{l}0.055 \\
0.040 \\
0.055\end{array}$ & $\begin{array}{l}23 \\
34 \\
13\end{array}$ & $\begin{array}{l}1.68 \\
1.58 \\
1.60\end{array}$ & \\
\hline トリメ゚フヨジイン & $\begin{array}{r}7 \\
8 \\
9 \\
101\end{array}$ & $\begin{array}{l}1900 \\
1960 \\
1860 \\
2200\end{array}$ & $\begin{array}{c}0.5 \% \\
" \\
0.1 \%\end{array}$ & $\begin{array}{c}0.2 \\
0.2 \\
0.5 \\
0.25\end{array}$ & $\begin{array}{l}1.320 \\
0.990 \\
1.320 \\
0.495\end{array}$ & $\begin{array}{l}33 \\
32 \\
38 \\
32\end{array}$ & $\begin{array}{l}0.83 \\
1.09 \\
0.69 \\
0.12\end{array}$ & \\
\hline$y,-N$ & $\begin{array}{r}34 \\
35 \\
36 \\
102\end{array}$ & $\begin{array}{l}1810 \\
2090 \\
2600 \\
2120\end{array}$ & $\begin{array}{c}0.5 \% \\
" \\
\% \\
0.1 \%\end{array}$ & $\begin{array}{l}0.2 \\
0.2 \\
0.5 \\
0.25\end{array}$ & $\begin{array}{l}0.855 \\
0.990 \\
1.155 \\
0.160\end{array}$ & $\begin{array}{l}174 \\
208 \\
131 \\
215\end{array}$ & $\begin{array}{l}1.04 \\
1.04 \\
0.98 \\
1.40\end{array}$ & \\
\hline エレクトラNゴ- & $\begin{array}{l}16 \\
17 \\
18\end{array}$ & $\begin{array}{l}2070 \\
1930 \\
2000\end{array}$ & & $\mid \begin{array}{l}0.2 \\
0.2 \\
0.5\end{array}$ & $\begin{array}{l}0.066 \\
0.066 \\
0.110\end{array}$ & $\begin{array}{r}10685 \\
8319 \\
6655\end{array}$ & $\begin{array}{l}2.12 \\
2.03 \\
1.92\end{array}$ & \\
\hline$=\Rightarrow x=-x$ & $\begin{array}{l}64 \\
65 \\
66 \\
90\end{array}$ & $\begin{array}{l}1900 \\
2153 \\
2070 \\
2150\end{array}$ & $\begin{array}{c}0.2 \% \\
" \\
1.0 \%\end{array}$ & $\begin{array}{l}0.2 \\
0.2 \\
0.3 \\
0.2\end{array}$ & $\begin{array}{l}0.495 \\
0.660 \\
0.495 \\
0.330\end{array}$ & $\begin{array}{l}2248 \\
3586 \\
8081 \\
3465\end{array}$ & $\begin{array}{l}1.77 \\
1.67 \\
1.56 \\
2.87\end{array}$ & . \\
\hline ヂスパルゲン & $\begin{array}{l}10 \\
11 \\
12\end{array}$ & $\begin{array}{l}1800 \\
2000 \\
1970\end{array}$ & $\begin{array}{c}2.0 \% \\
" 1 \\
"\end{array}$ & $\begin{array}{l}0.2 \\
0.2 \\
0.5\end{array}$ & $\begin{array}{l}0.250 \\
0.160 \\
0.160\end{array}$ & $\begin{array}{l}5178 \\
1272 \\
6752\end{array}$ & $\begin{array}{l}2.02 \\
2.62 \\
1.49\end{array}$ & \\
\hline$フ^{\circ} ロ x y^{*}-v$ & $\begin{array}{l}37 \\
38 \\
39\end{array}$ & $\begin{array}{l}1800 \\
1830 \\
2500\end{array}$ & $\begin{array}{c}0.1 \% \\
\% \\
\%\end{array}$ & $\begin{array}{l}0.2 \\
0.2 \\
0.2\end{array}$ & $\begin{array}{l}0.495 \\
0.495 \\
0.600\end{array}$ & $\begin{array}{l}10063 \\
17750 \\
10276\end{array}$ & $\begin{array}{l}1.22 \\
1.70 \\
1.69\end{array}$ & 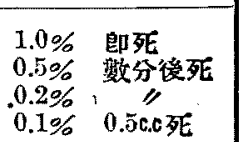 \\
\hline 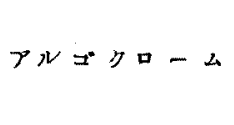 & $\begin{array}{l}61 \\
62 \\
63\end{array}$ & $\begin{array}{l}1800 \\
1830 \\
2150\end{array}$ & $\begin{array}{c}1.0 \% \\
\%\end{array}$ & $\begin{array}{l}0.2 \\
0.2 \\
0.4\end{array}$ & $\begin{array}{l}0.845 \\
0.845 \\
0.990\end{array}$ & $\begin{array}{l}463 \\
569 \\
688\end{array}$ & $\begin{array}{l}1.46 \\
0.91 \\
1.84\end{array}$ & 61 號200時間後死 \\
\hline メ゙チーレンブラウ & $\begin{array}{l}43 \\
44 \\
45\end{array}$ & $\begin{array}{l}1800 \\
1830 \\
1200\end{array}$ & $\begin{array}{c}1.0 \% \\
\%\end{array}$ & $\begin{array}{l}0.2 \\
0.2 \\
0.5\end{array}$ & $\begin{array}{l}0.660 \\
0.330 \\
0.495\end{array}$ & $\begin{array}{r}1592 \\
8.14 \\
1147\end{array}$ & $\begin{array}{l}1.68 \\
1,86 \\
1.09\end{array}$ & \\
\hline f & $\begin{array}{l}70 \\
71 \\
72\end{array}$ & $\begin{array}{l}1870 \\
1910 \\
1910\end{array}$ & $\begin{array}{c}0.1 \% \\
" \\
y\end{array}$ & $\begin{array}{l}0.2 \\
0.2 \\
0.4\end{array}$ & $\begin{array}{l}0.330 \\
0.330 \\
0.330\end{array}$ & $\begin{array}{l}359 \\
522 \\
438\end{array}$ & $\begin{array}{l}1.28 \\
1.50 \\
1.63\end{array}$ & $\begin{array}{ll}1.0 \% & \text { 即死 } \\
0.5 \% & 3 \text { 時間後死 }\end{array}$ \\
\hline
\end{tabular}




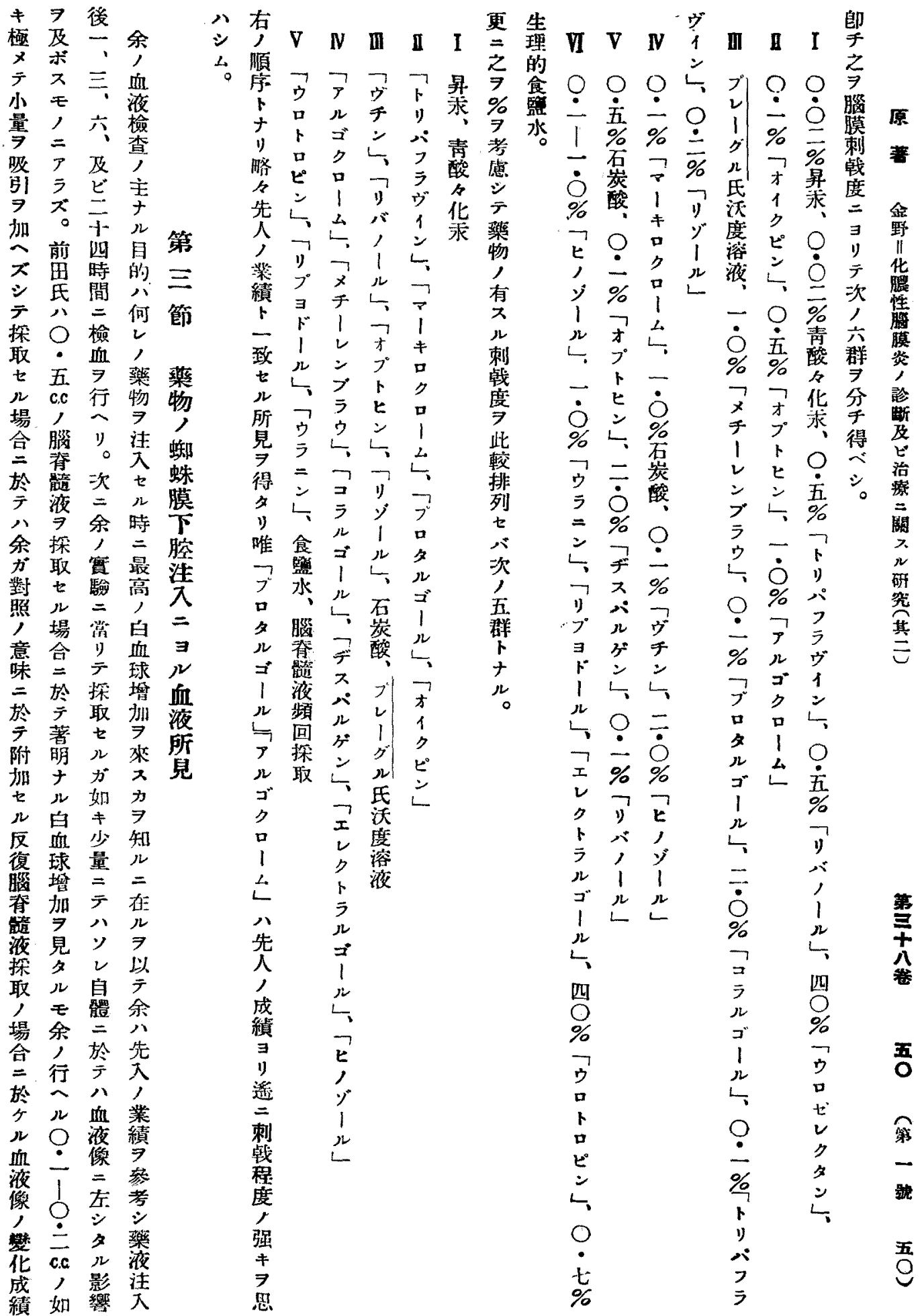




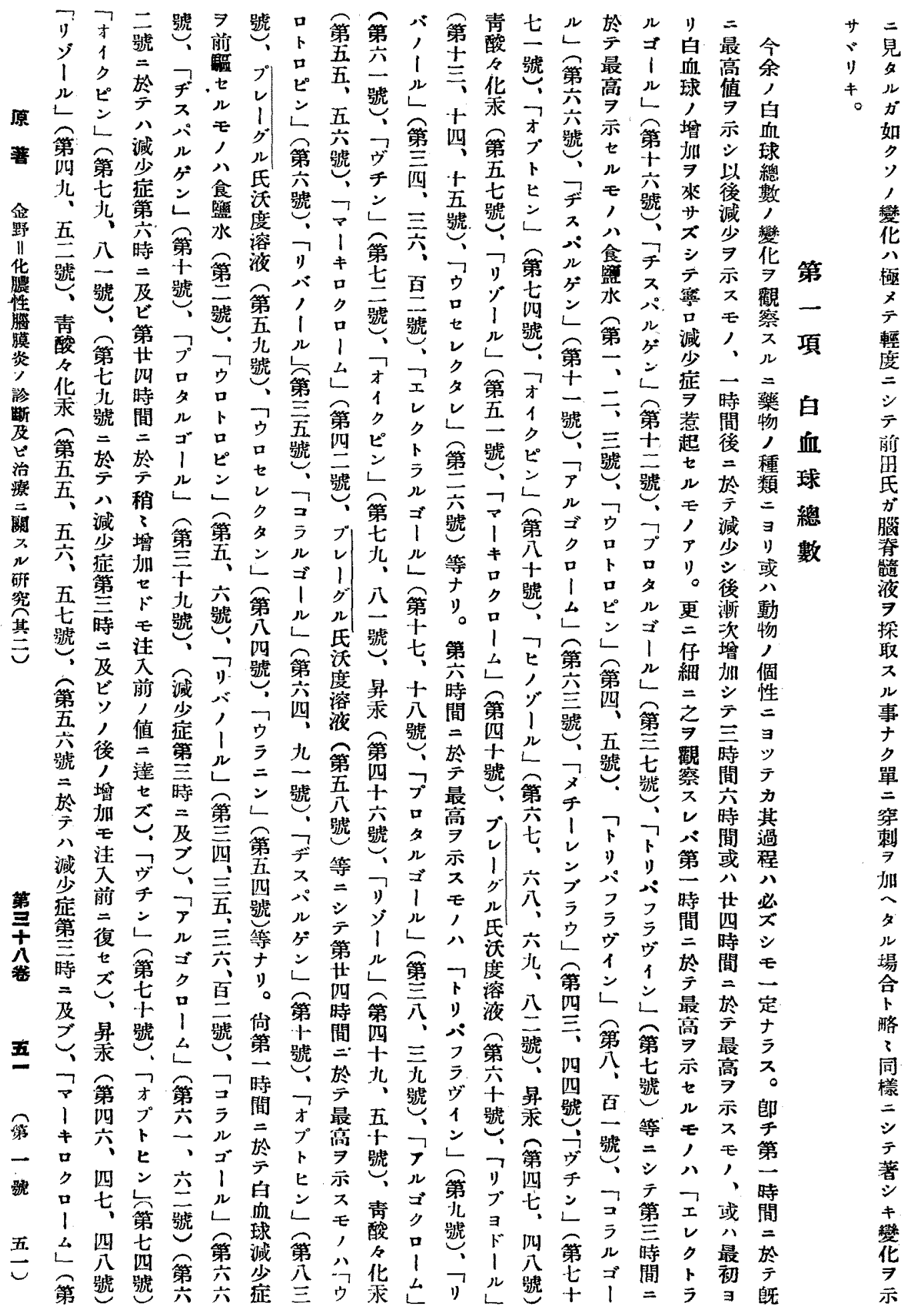


淋。郎 テ 數 假

巴0于 白, 性。次 球。反血增 ᄀ = 復球減工余 淋腦皨八才。分

导脊，多汸白

球 䯣,

, 液八シ

消探 $\bigcirc$ テ 些。種

長 取 | 本 好。類

八又 九 細 細。=

一 $\bigcirc$ 胞胞。關

般食\%系

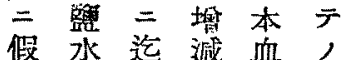

性乼及

工時事 $九$ 大

才二广卜體行

ジ於り稱二人

亡 テ倘得於号

嘹ソ木可白之

好, 又干血八

細百假モ球 略

胞分性然總

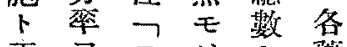

正 $尹$ 工

對加主消二

$ナ 七$ 血長就

》。苂球 $尹$ キ

然向好數三元

示細, 傾

圣胞袋白向

モ時 八加血

間白”球示

, , 血先總七

百經球云數”。

分過總悹瀿

率 共數

整三塯枀時

絶著加 $v=$

對奛七侣增

數ナザホ㧈

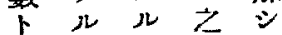

ガ核場二減

相合逮少

致偏 テテ

世位其持減

ザ 7 程 續 少

示度 ス

事 七 $儿 。$

厂》。堡事從

少多白

後場而球

者 合 總
度》民於二上第士モ中著造種燕夕四

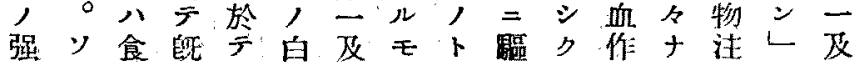
キ, 警二八血ビノ七逐內用儿入第ビ

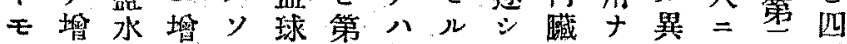

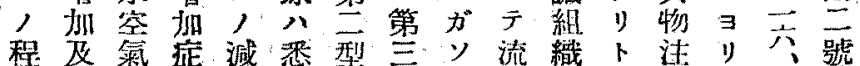
減ど习少り, 型, 血殊秘入テ 少娍 2 示及第多最後中 $=*=$ 白四

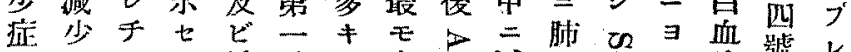

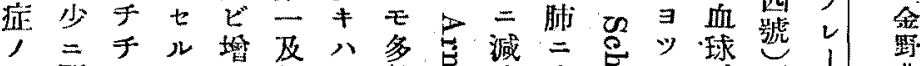

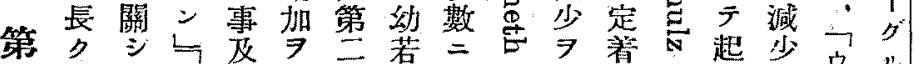
一螋

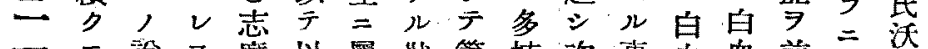

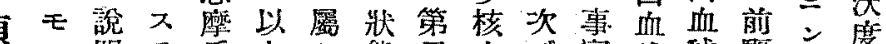
，明テ氏上シ態三白デ䔬球球駱它溶

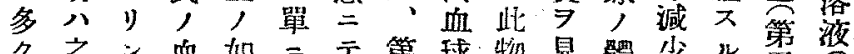

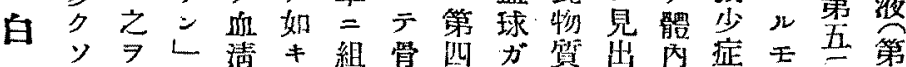

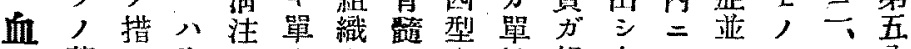
著キ全入ナ上济核組之於三、五八

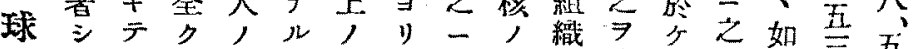

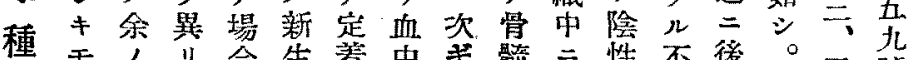
類, 成墨墨或省第細侵

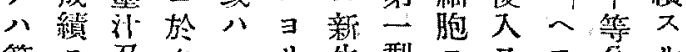
第二又ダフリ生型ヨスモ分ル

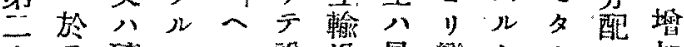

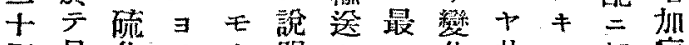

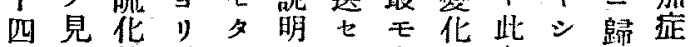
時第㒄 $キ$

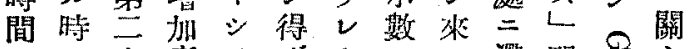

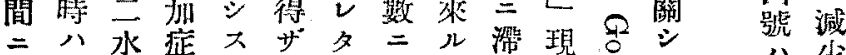

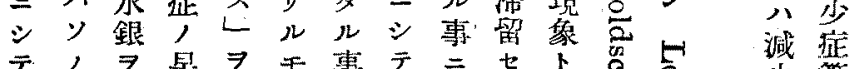

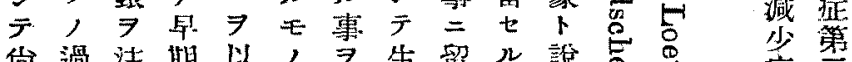

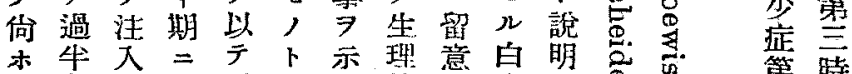
注数七起說棌入的要七血七第時

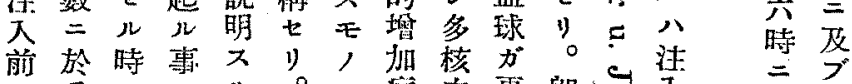

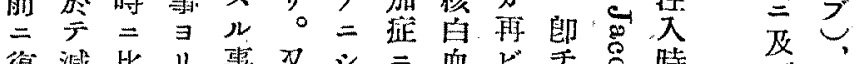

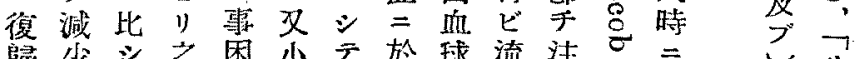

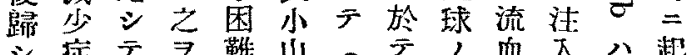

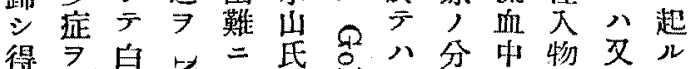

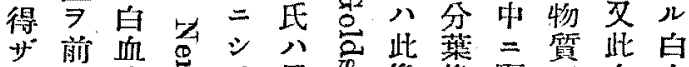

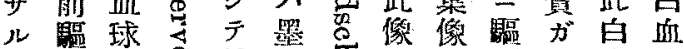

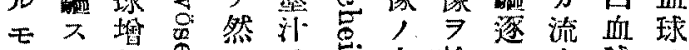

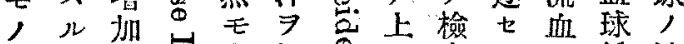

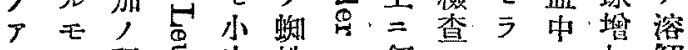
り, 程吉山蛛 。 = 度员氏膜等示第大, 現數十

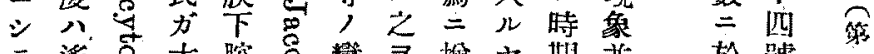

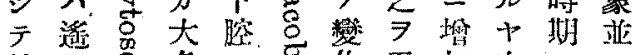

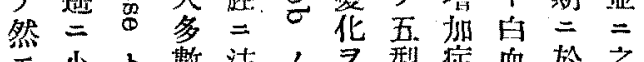

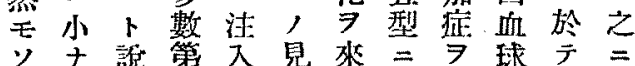

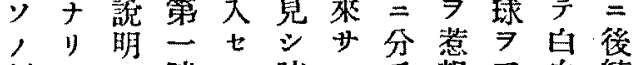
刺卜シ 時ル肺、手赸毛血續

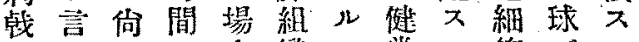

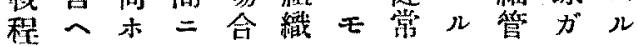

原 萧 华 哄 腰 炎 猃 路 及 治 療 開 四 號会研 第至基 五彪当 猋跳一 八 蜘 ウ

蛛 口

莫七五 腔 ク 


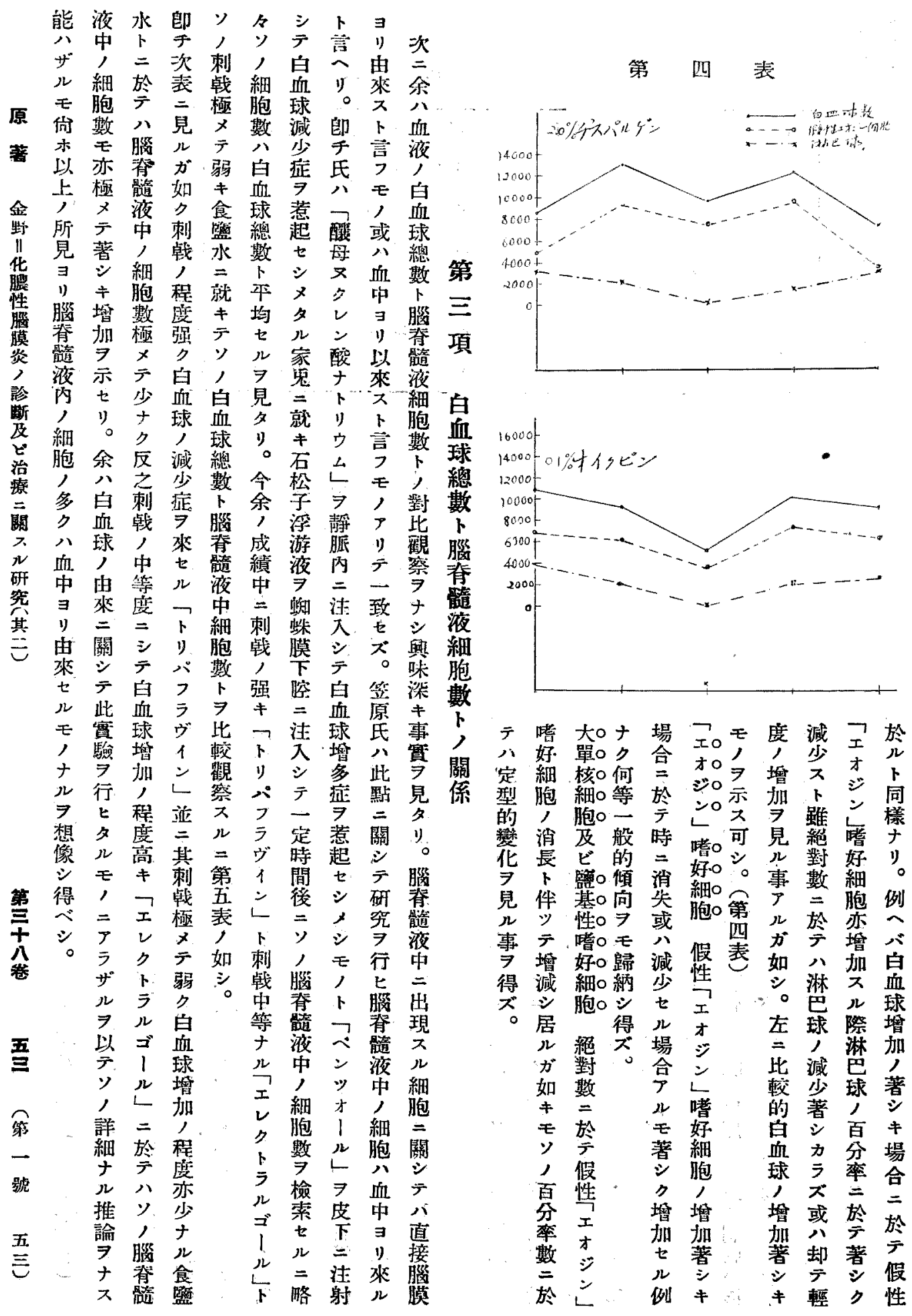




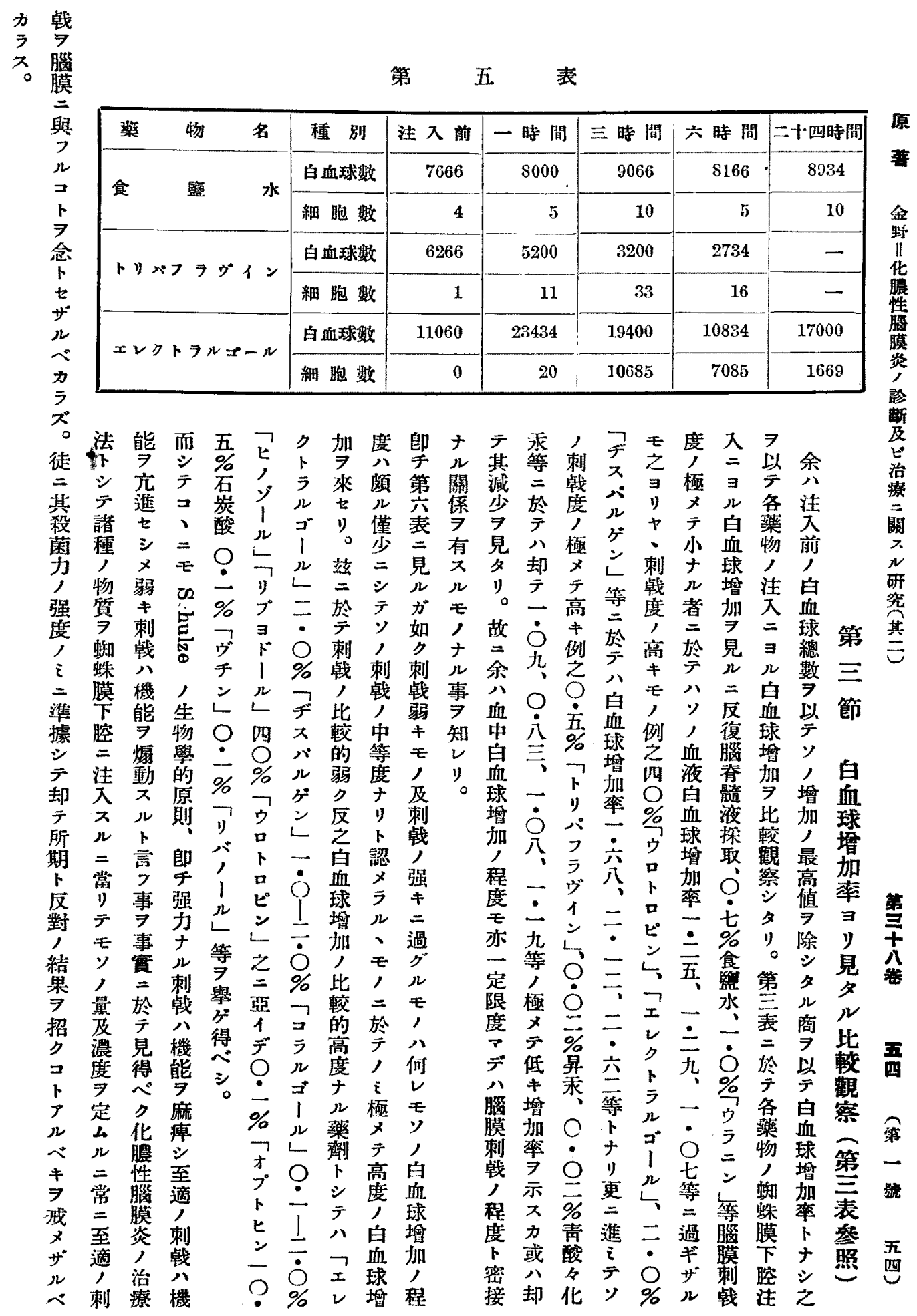


第六表

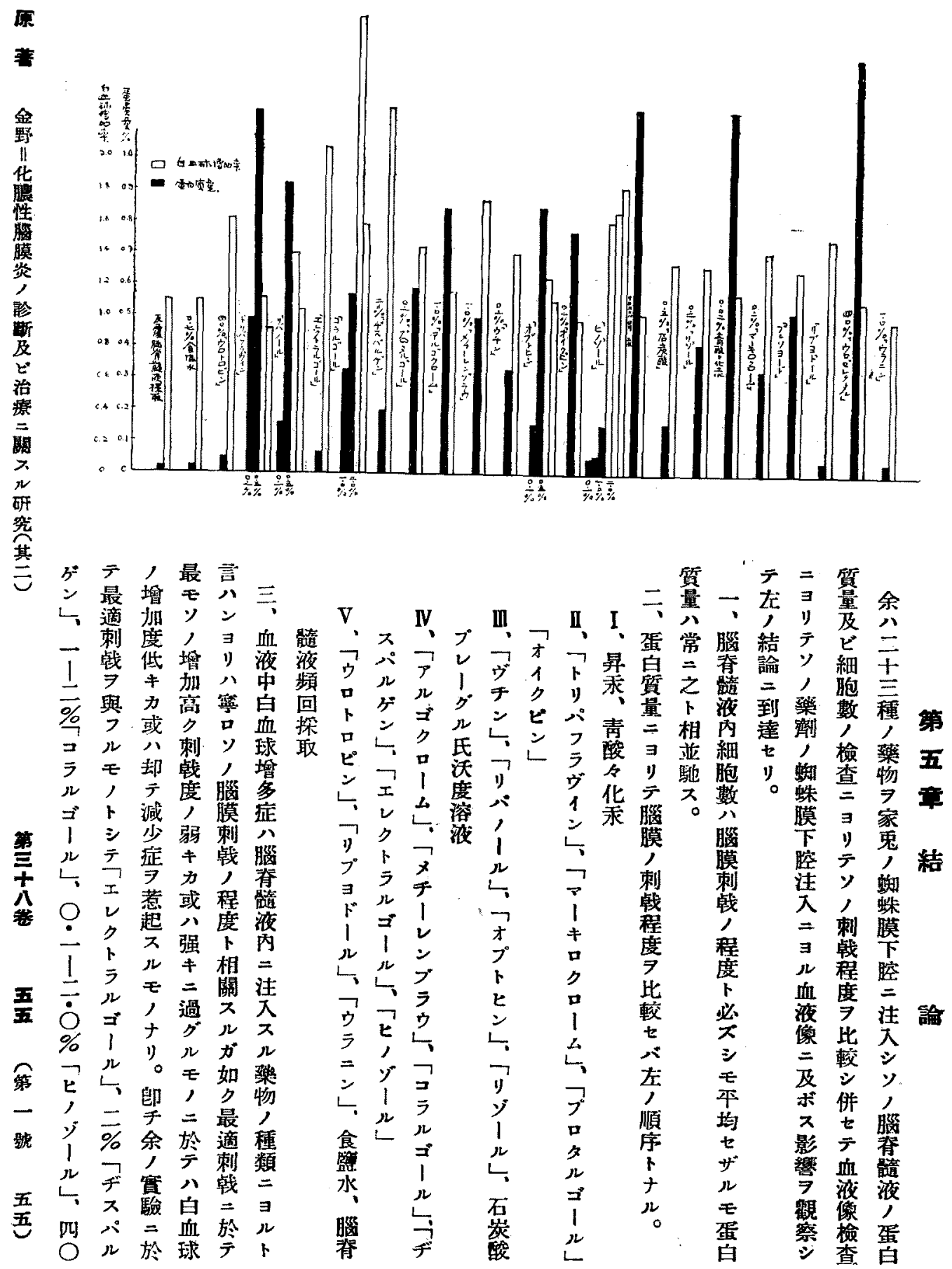




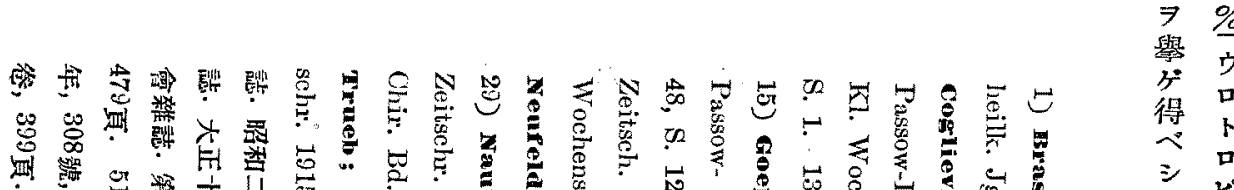

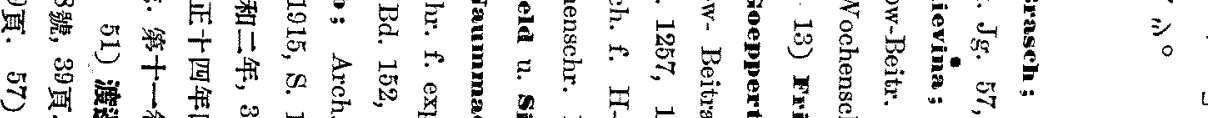

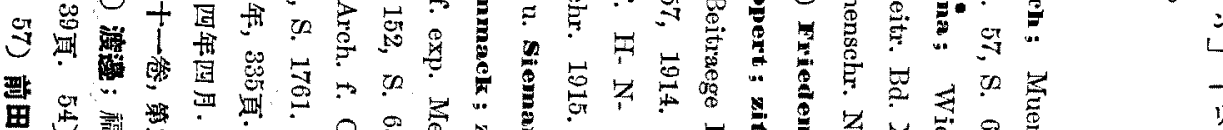

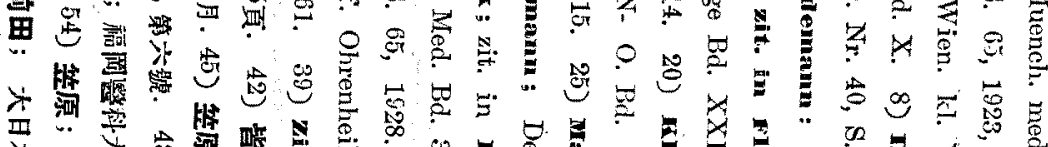

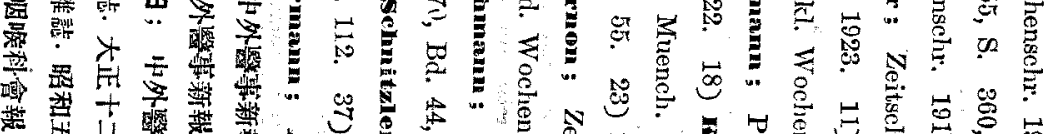

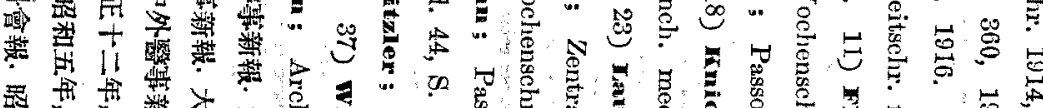

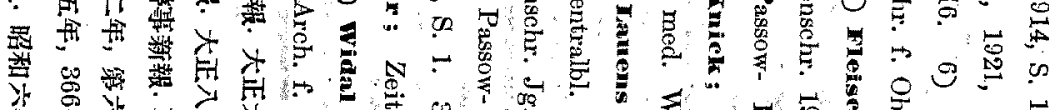

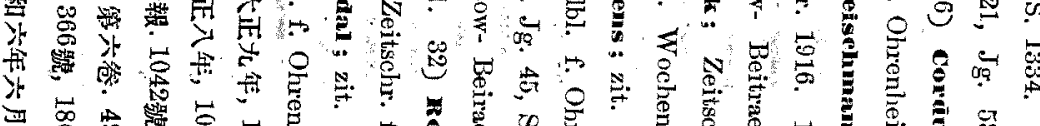

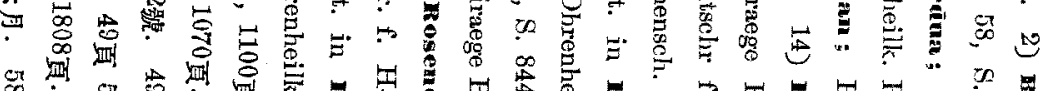

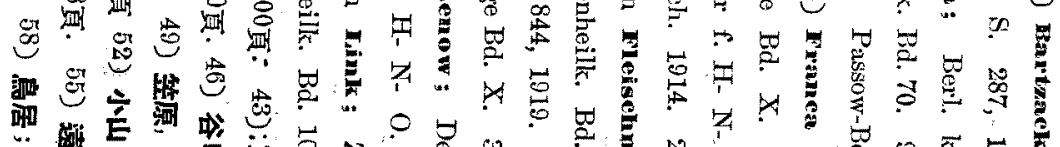

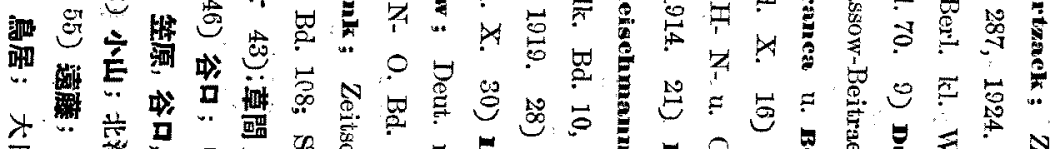

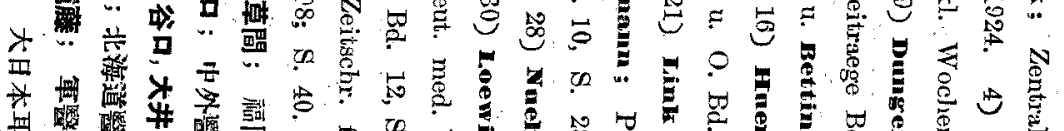

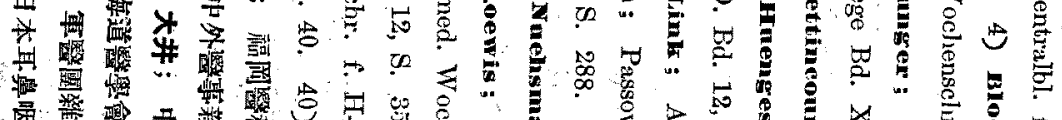

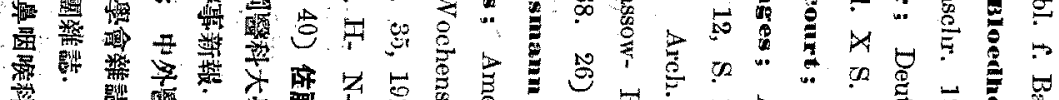

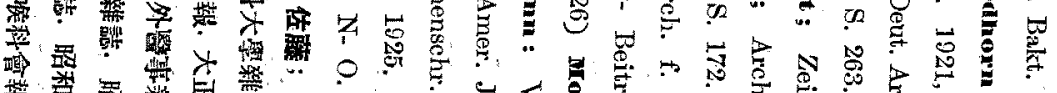

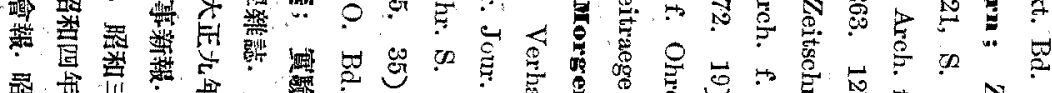

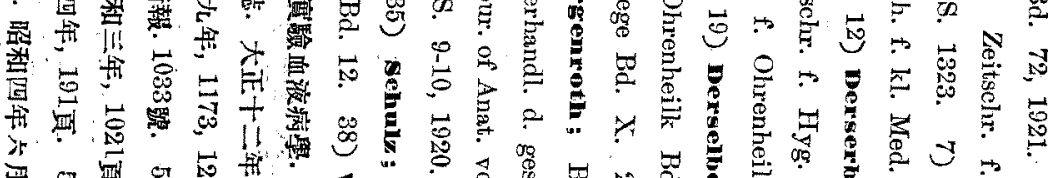

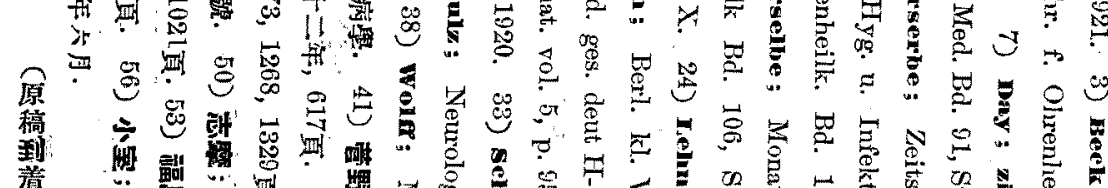

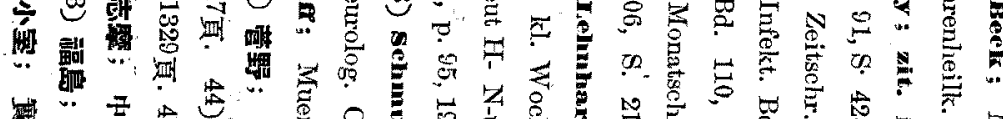

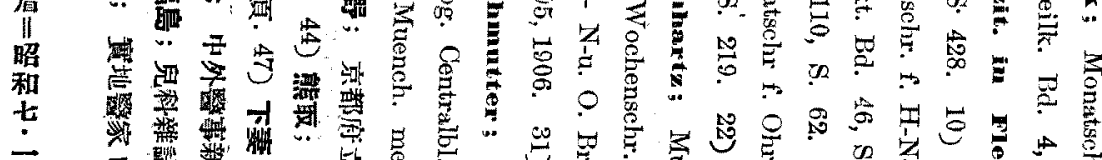

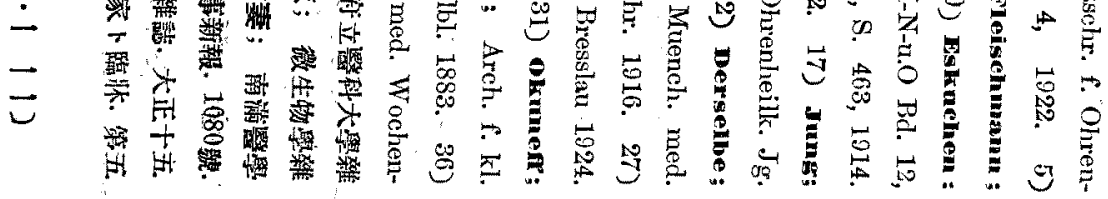


maessigem Reiz; bei zu schwachem oder zu starkem Reiz sieht man nur geringe Laucocytose oder sogar Leucopenie.

Aus diesem Experiment kann man als auf die Meningen einen mittelmaessigen Reiz ausuebende Medikamente nachfolgende herausziehen; Elektrargol, 2\% Dispargen, I-2\% Kollargol, O.I-2.0\% Chinosol und 40\% Urotropin, dann 0.1\% Rivanol, o.I Optochin, $0.5 \%$ Carool und $0.1 \%$ Vuzin.

(Autoreferat.)

\section{Beitraege zur Diagnose und Therapie der eitrigen Meningitis. (II. Mitteilung.)}

\section{Experimentelle Untersuchuug zur intralumbalen}

Therapie der eitrigen Meningitis.

\section{I. Untersuchung der Diffusionskraft der Medikam $\equiv n$ te. Von}

\section{Dr. I. Konno.}

(aus der oto- rhino- laryngologischen Klinik der medizinischen Fakultaet zu Niigata. Direktor; Prof. Dr. E. Torii.)

Wollen wir einen Medikament intralumbal anwenden, so sollen wir uns zunaechst seinen Verbreitungsmechanismus im Liqour klar machen. Frueher nahmen wir mit Unrecht an, dass die in den Liquor gebrachteten Medikamente entsprechend, der vorhandenen Liquormenge verduennt werden und sich in dieser Verduennung schliesslich gleichmaessig in die Ventrikel und Arachnoidealraeume verteilen. Aber spaetere experimentelle Untersuchungen zeigen uns, dass alle diese Annahmen falsch waren, naemlich die Verteilung der Substanzen im Liquor geht nicht nach dem Gesetz der Verduennung, sondern nach dem physikalischen Prinzip der Diffusion vor sich. (Lewandowski, Fleischmann).

Verfasser untersucht hier die Diffusibilitaet der schon genannten Medikamente.

I) Diffusionsgroesse der Medikamente.

Nach Michaelis und Rona fuellt man eine Reihe Reagenzglaeser mit einer ro cm hohen Schicht Io proz. Gelatineloesung. Nach ihrem Erstarren setzt man eine Menge der waesserigen Medikament-Loesung hinzu. Nach 24 Stunden misst man 

I) Reiz auf Meningen moeglichst wenig.
2) Leucocytose relativ gross.
3) Diffusionskraft im Liquor moeglichst gross.
4) Resorption am Liquor relativ traeg.
5) Bakterizide Kraft im Liquor starle.

\section{Untersuchungen ueber den Reiz der intralunbal injizierten Medikamente auf die Meningen.}

\section{1) Beobachtungen am Liquorbefund und Wirkung auf das Blutbild.}

Wollen wir zu therapeutischem Zweck die Medikamente intralumbal einfuehren, so muessen wir zuerst Reizgroesse derselbe auf die Meningen wissen. Bis heute sind solche Arbeiten nur durch Schmutter und Kasawara ausgefuehrt worden.

Tier: .Kaninchen, Koerpergewicht ca. 2 Kg. Gesamtzahl 93. Medikament, suboccipital, pro Kilo O.I-0.2., injiziert. Liquor in gleicher Weise einmal O.I-0.2 entnommen. Nach Zeitreihe, Ist, 3st., 6st. und 24st., werden Liquor (Zellenzahl und Eiweissgehalt) und Blut (Leucocytenzahl und Zellarten) beobachtet.

Medikamente: Urotropin, Trypaflavin, Rivanol, Elektrargol, Kollargol, Dispargen, Protargol, Argochrom, Methylenblau, Vuzin, Optochin, Eucupin, Chinosol, Sublimat, Carbol, Lysol, Quecksilberoxycyanid, Mercurochrom und Spezijod, Lipjodol, Uroselektan und Uranin, als Kontrolle $0.7 \%$ physiologische Kochsalzloesung. Widerholte suboccipitale Punktion.

Die Resultate sind folgende;

I) Der Eiweissgehalt im Liquor verlauft immer mit dem Grad des Reizes parallel, aber die Zellzahl meistens nicht.

2) Wenn man die Reizstaerke auf die Meningen der intralumbal injizierten Medikamente auf Grund des Eiweissgehaltes im Liquor beobachtet, kann man folgende 5 Gruppen feststellen:

I) Sublimat, Quecksilberoxycyanid.

II) Trypflavin, Mercurochrom, Protargol, Eucupin.

III) Vuzin, Rivanol, Optochin, Lysol, Carbol, Presojod.

IV) Argochrom, Methylenblau, Kollargol, Dispargen, Flektrargol, Chinosol.

V) Urotropin, Lipjodol, Uranin, physiologische Kochsalzloesung, wiederholte suboccipitale Punktion.

3) Die Laukocytose im Blut beruht nicht nur auf dem Medikament, sondern auf der Reizbarkeit der Meningen. Die staerkste Leucocytose kommt bei mittel- 
g) Bakterien: sind in allen Faeilen, ausser dem I. Fall, nachgewiesen.

2) Blutbild:

Gesamte Leucocytenzahl ausserordentlich vermehrt bis zu 20000-50000 im Endstadium. Diese Gesamtzahl geht immer parallel mit der Prozentzahl der pseudoeosinophillen Zellen, im Gegenteil mit dem der Lymphocyten. Grosse Monozyten und basophile Zellen zeigen Schwankung.

3) Die Senkungsgeschwindigkeit der roten Blutkoerperchen:

beschleunigt immer parallel dem Krankheitsverlauf.

4) Harn:

Eiweiss von Anfang an wenig, Zucker positiv bei 9 Faellen, Aceton positiv nur bei I. Fall, Kreatinin ganz normal, Urobilinogen- Weiss'- und Indikanreaktion immer negativ.

5) Auge :

bei 2 I Faellen findet man stets irgendeine Veraenderung des Augenhintergrundes; I 3 Stauungspapille, 7 Neuritis optica, I Anaemie des r. Fundus.

Aus obigen Resultaten kann man folgende klinisch wichtigen Punkte herausziehen ;

Eiweiss-, Chlorid- und Cakziumgehalt und Wasserstoffionenkonzentration im Liquor, Verhaeltnisse der Leucozytenzahl und Lymphocyten, Verminderung der eosinophilen Zellen im Blute, Senkungsgeschwindigkeit der roten Blutkoerperchen und Veraenderung des Fundus. Wichtige Anhaltspunkte zur Diagnose und Prognose der Meningitis.

(Aztoreferat.)

\section{Beitraege zur Diagnose und Therapie der eitrigen Meningitis. (II, Mitteillung.)}

Experimentelle Untersuchung zur intralumbalen Therapie der eitrigen Meningitis.

Von

\section{Dr. I. Konno.}

(aus der oto-rhino-laryngologischen Klinik der medizinischen Fakultaet zu Nilgata. Direktor; Prof. Dr. E. Torii.)

Verfasser gibt 5 wichtige Eigenschaften von Medikamenten bei intralumbaler Anwendung an, d.h. 